\title{
Article
}

\section{Digital Immunophenotyping Predicts Disease Free and Overall Survival in Early Stage Melanoma Patients}

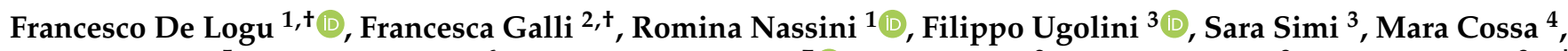 \\ Clelia Miracco ${ }^{5}$, Andrea Gianatti ${ }^{6}$, Vincenzo De Giorgi ${ }^{7}$ (1), Eliana Rulli ${ }^{2}$, Antonio Cossu ${ }^{8}$, Daniela Massi ${ }^{3, *, \ddagger}$ \\ and Mario Mandalà $9,10, *, \ddagger$
}

check for updates

Citation: De Logu, F.; Galli, F.; Nassini, R.; Ugolini, F.; Simi, S.; Cossa, M.; Miracco, C.; Gianatti, A.; De Giorgi, V.; Rulli, E.; et al. Digital Immunophenotyping Predicts

Disease Free and Overall Survival in Early Stage Melanoma Patients. Cells 2021, 10, 422. https://doi.org/ $10.3390 /$ cells 10020422

Academic Editors: Shikhar Mehrotra and Anna Sapino

Received: 13 January 2021

Accepted: 10 February 2021

Published: 17 February 2021

Publisher's Note: MDPI stays neutral with regard to jurisdictional claims in published maps and institutional affiliations.

Copyright: (c) 2021 by the authors. Licensee MDPI, Basel, Switzerland. This article is an open access article distributed under the terms and conditions of the Creative Commons Attribution (CC BY) license (https:/ / creativecommons.org/licenses/by/ $4.0 /)$.
1 Section of Clinical Pharmacology and Oncology, Department of Health Sciences, University of Florence, 50100 Florence, Italy; francesco.delogu@unifi.it (F.D.L.); romina.nassini@unifi.it (R.N.)

2 Methodology for Clinical Research Laboratory, Oncology Department, Istituto di Ricerche Farmacologiche Mario Negri IRCCS, 20156 Milan, Italy; francesca.galli@marionegri.it (F.G.); eliana.rulli@marionegri.it (E.R.)

3 Section of Pathological Anatomy, Department of Health Sciences, University of Florence, 50100 Florence, Italy; filippo.ugolini@unifi.it (F.U.); sara.simi@unifi.it (S.S.)

4 Department of Pathology, Fondazione IRCCS Istituto Nazionale dei Tumori, 20133 Milan, Italy; mara.cossa@istitutotumori.mi.it

5 Unit of Pathological Anatomy, Department of Medicine, Surgery, and Neurosciences, University of Siena, 53100 Siena, Italy; clelia.miracco@ao-siena.toscana.it

6 Pathology Unit, Papa Giovanni XXIII Hospital, 24127 Bergamo, Italy; agianatti@asst-pg23.it

7 Dermatology Unit, University of Florence, 50100 Florence, Italy; vincenzo.degiorgi@unifi.it

8 Section of Pathology, Department of Medical, Surgical and Experimental Sciences, University of Sassari, 07100 Sassari, Italy; cossu@uniss.it

9 Division of Pathological Anatomy, Papa Giovanni XXIII Hospital, 24127 Bergamo, Italy

10 Unit of Medical Oncology, University of Perugia, 06123 Perugia, Italy

* Correspondence: daniela.massi@unifi.it (D.M.); mmandala@asst-pg23.it (M.M.)

+ FDL and FG shared first Authorship and equally contributed to the study.

$\ddagger \quad \mathrm{DM}$ and $\mathrm{MM}$ shared last Authorship and equally contributed to the study.

Abstract: Background: the prognostic significance of tumor infiltrating lymphocytes (TILs) in intermediate/thick primary cutaneous melanoma (PCM) remains controversial, partially because conventional evaluation is not reliable, due to inter-observer variability and diverse scoring methods. We aimed to assess the prognostic impact of the density and spatial distribution of immune cells in early stage intermediate/thick PCM. Materials and Methods: digital image acquisition and quantitative analysis of tissue immune biomarkers (CD3, CD4, CD8, CD68, PD-L1, CD163, FOX-P3, and PD-1) was carried out in a training cohort, which included patients with primary $\mathrm{PCM} \geq 2 \mathrm{~mm}$ diagnosed, treated, and followed-up prospectively in three Italian centers. Results were validated in an independent Italian cohort. Results: in the training cohort, 100 Stage II-III melanoma patients were valuable. At multivariable analysis, a longer disease free survival (DFS) was statistically associated with higher levels of $\mathrm{CD}^{+}{ }^{+}$intratumoral T-cells (aHR [100 cell $/ \mathrm{mm}^{2}$ increase] $0.98,95 \% \mathrm{CI} 0.95-1.00, p=0.041$ ) and CD163 ${ }^{+}$ inner peritumoral (aHR [high vs. low] 0.56, 95\%CI 0.32-0.99, $p=0.047$ ). A statistically significant longer DFS (aHR [high-high vs. low-low] 0.52, 95\%CI 0.28-0.99, $p=0.047$ ) and overall survival (OS) (aHR [high-high vs. low-low] $0.39,95 \%$ CI $0.18-0.85, p=0.018$ ) was found in patients with a high density of both intratumoral $\mathrm{CD} 8^{+} \mathrm{T}$-cells and $\mathrm{CD}^{+} 8^{+}$macrophages as compared to those with low density of both intratumoral $\mathrm{CD} 8^{+} \mathrm{T}$-cells and $\mathrm{CD}^{+} 8^{+}$macrophages. Consistently, in the validation cohort, patients with high density of both intratumoral $\mathrm{CD}^{+}$and $\mathrm{CD}^{+} \mathrm{T}$-cells were associated to a statistically better DFS (aHR[high-high vs. low-low] 0.24, 95\%CI 0.10-0.56, $p<0.001$ ) and those with high density of both intratumoral $\mathrm{CD}^{+}$and $\mathrm{CD}^{+} 8^{+}$were associated to a statistically longer OS (aHR[high-high vs. low-low] $0.28,95 \% \mathrm{CI} 0.09-0.86, p=0.025)$. Conclusion: our findings suggest that a specific preexisting profile of $\mathrm{T}$ cells and macrophages distribution in melanomas may predict the risk of recurrence and death with potential implications for the stratification of stage II-III melanoma patients.

Keywords: melanoma; digital pathology; tumor infiltrating lymphocytes 


\section{Introduction}

The immune system plays an acknowledged role in melanoma development, progression and response to treatment [1-3]. Nevertheless, no biomarker has so far been translated so far into the clinic to define tumor immunity in individual patients. Instead, recognizing which patient has a "competent" immune system, prone to contribute to tumor control would help predicting patients who ultimately recur after surgery and those who do not. Melanoma is an archetype of immune surveillance theory, and it is recognized as one of the most immunogenic tumors [4].

The metastatic growth is a multistep process that involves interactions between the tumor and immune system [5]. As for other tumors, mortality is essentially linked to metastatic spread to sites that are distant from the primary tumor. Prognosticating outcome in early stage cutaneous melanoma is of paramount importance for several reasons: (i) to determine the need for further work-up investigations, (ii) to guide appropriate adjuvant treatment, (iii) to counsel patients, and (iv) to stratify those who enter clinical trials.

The conventional clinical and histopathological features that predict prognosis in primary cutaneous melanoma (PCM) include Breslow thickness (BT), ulceration, and sentinel lymph node (SN) status [6]. The presence of tumor infiltrating lymphocytes (TILs) in melanoma has been associated with a favorable prognosis in some studies [7-13] and implying a more effective host immunologic response to the tumor. However, other studies have failed to confirm such correlation [14,15], and the prognostic significance of TILs in thin vs. intermediate/thick PCM remains controversial.

TILs are a heterogeneous group of immune cells in the context of the tumor microenvironment mainly comprising of T-lymphocytes, and their assessment is subject to inter-observer variability, which can limit their applicability in routine use [15]. Among the immune cells that re recruited in the tumor microenvironment, macrophages are particularly abundant. Clinical and preclinical studies suggest that macrophages generally play a pro-tumoral role, by stimulating angiogenesis, enhancing tumor cell invasion, motility, and intravasation [16]. Spatial information and making inferences about the interactions of different immune cells, including macrophages with immunogenic and immunosuppressive functions, in the tumor tissue could represent a better way to investigate this complex scenario [17].

In order to assess the prognostic impact of the density and spatial distribution of immune cells in early stage intermediate/thick PCM, we herein evaluated TILs and macrophages by immunohistochemistry, digital image acquisition, and quantitative analysis to identify essential tissue immune biomarkers that are able to capture the immune contexture of the tumor microenvironment that could independently predict DFS and OS.

\section{Materials and Methods}

\subsection{Patients Characteristics}

The cohort of the training set $(n=100)$ included patients with stage II-III intermediate/thick PCM $\geq 2 \mathrm{~mm}$ diagnosed, treated, and followed-up prospectively in four Italian centres (Istituto Nazionale Tumori, Milan; Dermatology Section, University of Florence, Florence, University of Sassari, Sassari and University Hospital of Siena, Siena, Italy) from 2000 to 2015. The clinical and histopathological parameters that were extracted from the database included: gender, date of birth, date of diagnosis of PCM, date of SN biopsy, BT, ulceration, SN status, surgical procedures, TILs, and follow-up, including the date of relapse and death. Haematoxylin and eosin slides were reviewed, and the histopathological features were re-assessed by two dedicated dermatopathologists (DM, MC). The tumor stage was assessed according to the American Joint Committee on Cancer (AJCC) TNM (Tumor, Node, Metastasis) [18]. The tumors were re-evaluated for lymphocytic infiltration in the vertical growth phase (VGP), and classified as brisk, non-brisk, and absent according to criteria that were formulated by Clark et al. [19]. Lymphocytes had to surround and disrupt tumor cells in the VGP to be defined as TILs. These lymphocytes were termed "brisk" if they infiltrated the entire invasive component diffusely or across the base of the 
VGP. TILs were "absent" if no lymphocytes were present or if they were present, but did not infiltrate the tumor. When lymphocytes only infiltrated the melanoma focally with one or scattered foci, the term "non-brisk" was used.

The patients included in the validation cohort $(n=74)$ were treated at the Papa Giovanni XXIII Cancer Center Hospital, Bergamo, Italy. Similarly, to the training cohort, patients with BT $\geq 2 \mathrm{~mm}$ and with available tissue samples were included. Information on demographics as well as data on DFS and OS were retrieved for each patient. Data on treatment and survival were prospectively collected in the context of Melanoro project, as previously reported [14].

\subsection{Tissue Samples}

Formalin fixed paraffin-embedded (FFPE) tissue sections, $4 \mu \mathrm{m}$ in thickness, were stained with haematoxylin and eosin and reviewed to confirm the histopathological diagnosis and assess tissue quality control.

\subsection{Ethical Committee}

Approval to conduct the study was obtained from the local Ethics Committees of the participating Centers. Specifically, the use of FFPE sections of human samples was approved by the Local Ethics Committee (13676_bio, protocol Id.21073) according to the Helsinki Declaration and informed consent was obtained.

\subsection{Immunohistochemistry}

Tumor immune infiltrate characterization was performed by evaluating eight immune cell markers (CD3, CD4, CD8, FOX-P3, PD-L1, PD-1, CD68, and CD163) via immunohistochemistry on representative FFPE whole tumor sections 3- $\mu \mathrm{m}$ thick of PCM. The sections were deparaffinized in EZ prep (950-102; Ventana), and antigen retrieval was achieved by incubation with cell-conditioning solution 1 (950-124; Ventana), a Tris ethylenediaminetetraacetic acid-based buffer ( $\mathrm{pH} 8.2$ ), for $32 \mathrm{~min}$. at $100^{\circ} \mathrm{C}$ or with Dako PT-link, EnVision ${ }^{\mathrm{TM}}$ FLEX Target Retrieval Solution, Low $\mathrm{pH}$. Sections were incubated with the following primary antibodies: anti-CD3 (\#790-4341, rabbit monoclonal, clone 2GV6 ready to use, Ventana Medical System, Tucson, AZ, USA), anti-CD4 (\#790-4423, rabbit monoclonal, clone SP35, ready to use, Ventana Medical System, Tucson, AZ, USA), anti-CD8 (\#790-4460, rabbit monoclonal, clone SP57, ready to use, Ventana Medical System, Tucson, AZ, USA), and anti-FOX-P3 (\#b20034, mouse monoclonal, clone 236A/E7, 1:60. Abcam, Cambridge, UK). The signal was developed with the UltraMap Red anti-Mouse or anti-Rabbit Detection Kit (Ventana Medical Systems, Tucson, AZ, USA) in an automated Immunostainer (Ventana Discovery XT, Ventana Medical Systems, Tucson, AZ, USA). In addition, the sections were incubated with the following primary antibodies: anti-PD-L1 (clone 22c3 Dako Agilent, dilution 1:25), anti-PD1 (clone NAT105 Biocare; dilution 1:50), anti-CD68 (clone KP1, Dako Agilent, dilution 1:3000), and anti-CD163 (clone 10D6, Novus Biological, dilution 1:200). The signal was developed with EnVision ${ }^{\mathrm{TM}}$ FLEX+, Dako, Agilent) in an automated Immunostainer (Dako Autostainer Link 48). The sections were counterstained with hematoxylin. Appropriate positive controls were used throughout.

Immunohistochemical scoring was performed in a blinded fashion by experienced melanoma pathologists (DM, MC). Stained sections were initially assessed at low magnification in order to select the areas with highest density of positive immune cells at peritumoral and intratumoral location. The assessment of immune cells score density was compared with evaluation that was obtained by image analysis. An evaluation of PD-L1 was performed in both immune cells and tumor cells, as previously described [20].

\subsection{Image Analysis}

Stained tissue sections were digitally scanned at $\times 400$ magnification with Aperio AT2 or Aperio ScanscopeXT platform (Leica Biosystems, Wetzlar, Germany) into whole slide digital images (WSI). Each SVS format file was imported into HALO Link ${ }^{\circledR}$ (Indica Labs, 
Albuquerque, NM) image management system. Two expert pathologists (DM, MC) drew the image annotations of the whole surface and margins of PCM. The whole tumor area was defined as the area containing invasive tumor, including the invasive tumor borders, according to ITWG recommendations.

For all WSI, three different annotation layers were created, one for the intratumoral area and two, respectively, for the inner peritumoral area and outer peritumoral area, starting from the tumor border with a thickness of $250 \mu \mathrm{m}$ (Figure 1). The detection of immune-stained positive cells, in the three different layers, was performed using HALO $^{\circledR}$ Multiplex IHC analysis software version v3.1.1076.308 (Indica Labs, Albuquerque, NM), based on cytonuclear features, such as stain intensity, size, and roundness for CD3, CD4, CD8, FOX-P3 CD68, CD163, PD-1, and PD-L1. The software automatically excludes tissue gaps from analysis and the settings were set-up to include the full range of staining intensity (from weak to strong). The data were expressed as cellular density (i.e., the number of positive cells divided by the $\mathrm{mm}^{2}$ of the annotation layer area).
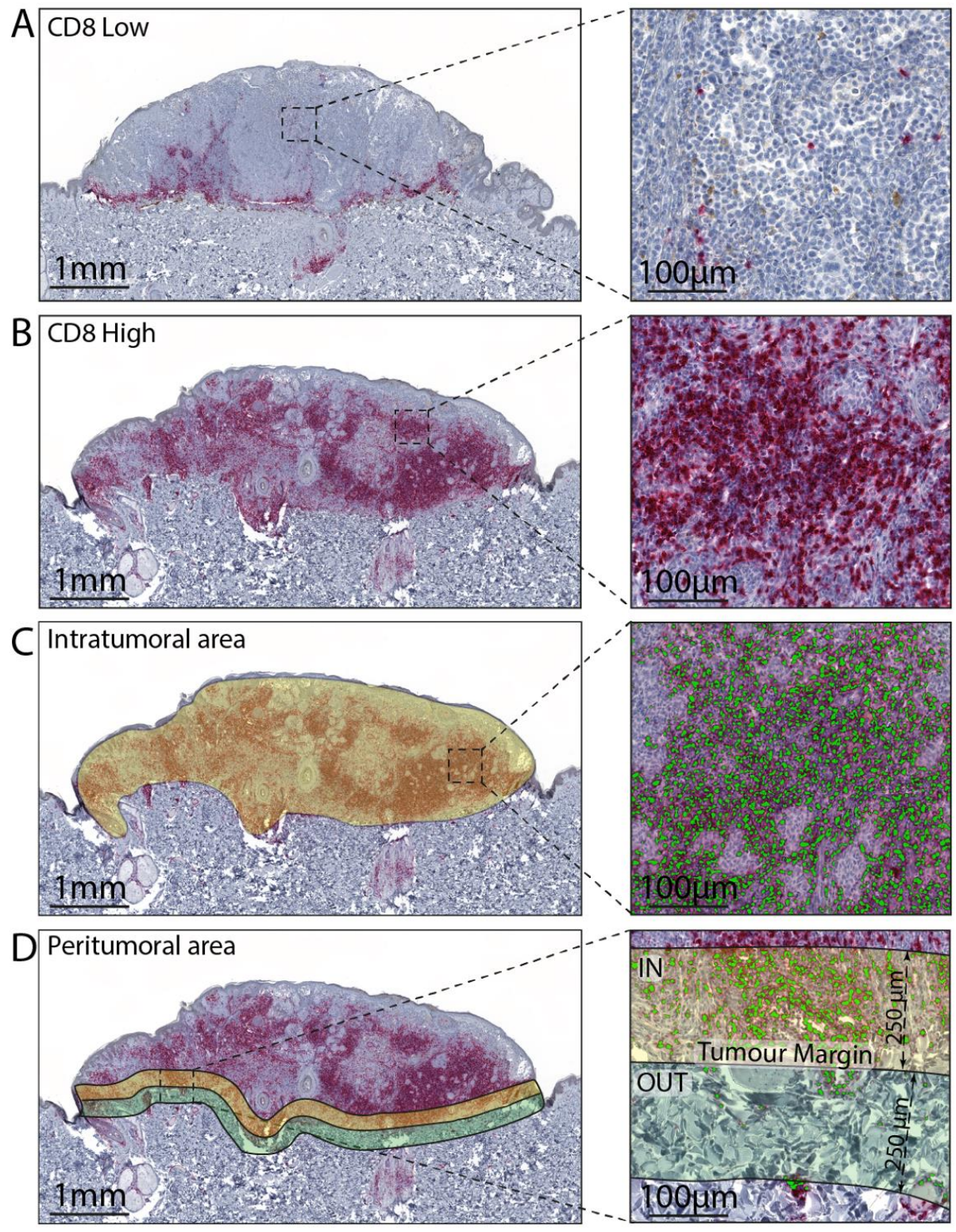

Figure 1. Representative images of melanoma tissue with low (A) and high (B) CD8 positive cells. (C) Representative annotation mask for intratumoral area and CD8 cells software recognition. (D) Representative annotation mask for inner (yellow, IN) and outer (green, OUT) portion of the peritumoral area and CD8 cells software recognition. 


\subsection{Statistical Analysis}

The aim of this study was to evaluate the prognostic value of intratumoral and peritumoral immune cell density on DFS and OS in intermediate/thick PCM. DFS was defined as the time between diagnosis and disease relapse or death from any cause. OS was defined as the time between diagnosis and death from any cause. Patients who had not relapsed/died or died were censored at the date of the last follow-up visit. Each immune cell biomarker was evaluated as a continuous variable and then categorized as low or high according to its median.

Continuous variables were described using mean and standard deviation (SD), the median with the first and third quartiles (Q1-Q3; interquartile range, $\mathrm{IQR}$ ), and minimum and maximum values, whereas the categorical variables were described using frequencies and percentages. Chi-square and Wilcoxon tests were performed in order to compare the distributions of categorical and continuous variable, respectively. The association between the immune cell biomarkers was assessed by means of the Spearman correlation index. A MANOVA analysis was performed for each immune cell biomarker to investigate the difference between intratumoral, inner and outer peritumoral area in terms of cells density. DFS and OS was evaluated using the univariable and multivariable Cox proportional hazard models.

Multivariable models were adjusted for the BT, the ulceration, and stage. The results of the analyses were expressed as hazard ratios (HRs), adjusted HRs (aHRs), and 95\% confidence intervals (95\%CIs). The median DFS and OS were estimated with the KaplanMeier (KM) method. The same analysis carried out for the training cohort was adopted for the validation cohort using, as biomarker cut-offs, those calculated in the training cohort. Statistical significance was set at $p<0.05$ for a bilateral test. Analysis was carried out using the SAS (Statistical Analysis System, SAS Institute, Version 9.4) software.

\section{Results}

\subsection{Training Cohort}

Overall, 100 stage II-III melanoma patients with BT $\geq 2 \mathrm{~mm}$ were included in the training cohort. Table 1 summarizes the demographical and clinical characteristics, whereas Table 2 provides the distribution of the biomarkers. The mean age of the patients was 63.2 years (SD 16.1), and 62 patients $(62.0 \%)$ were male. Tables S1 and S2 report the association between the density of immune cells and their correlation with stage, BT, and ulceration. The median follow-up was 83.9 months (IQR 64.5-111.6). Overall, 46 patients (46.0\%) relapsed, 52 patients $(52.0 \%)$ died, and 52 patients $(52.0 \%)$ relapsed or/and died (i.e., DFS events). The median DFS and OS were 38.4 months (IQR 12.2-129.7) and 85.7 months (IQR 38.0-162.2), respectively.

Table 1. Demographic and clinical characteristics.

\begin{tabular}{|c|c|c|c|}
\hline Variable & $\begin{array}{l}\text { Training Cohort } \\
\qquad N=100\end{array}$ & $\begin{array}{l}\text { Validation Cohort } \\
\qquad N=74\end{array}$ & $\begin{array}{c}\text { Chi-Squared or Wilcoxon } \\
p \text {-Value }\end{array}$ \\
\hline Centre & & & - \\
\hline University Hospital of Siena & $15(15.0)$ & $0(0.0)$ & \\
\hline University of Florence & $42(42.0)$ & $10(13.5)$ & \\
\hline University of Sassari/NRC & $43(43.0)$ & $0(0.0)$ & \\
\hline $\begin{array}{c}\text { Papa Giovanni XXIII Hospital, } \\
\text { Bergamo }\end{array}$ & $0(0.0)$ & $64(86.5)$ & \\
\hline Age & & & 0.619 \\
\hline Mean (SD) & $63.2(16.1)$ & $61.4(18.6)$ & \\
\hline Median (Q1-Q3) & $66.0(50.3-75.3)$ & $65.8(46.3-78.2)$ & \\
\hline Min-Max & $24.0-89.4$ & $21.9-88.1$ & \\
\hline Sex & & & 0.486 \\
\hline Female & $38(38.0)$ & $32(43.2)$ & \\
\hline Male & $62(62.0)$ & $42(56.8)$ & \\
\hline
\end{tabular}


Table 1. Cont.

\begin{tabular}{|c|c|c|c|}
\hline Variable & $\begin{array}{c}\text { Training Cohort } \\
\qquad N=100\end{array}$ & $\begin{array}{c}\text { Validation Cohort } \\
\qquad N=74\end{array}$ & $\begin{array}{c}\text { Chi-Squared or Wilcoxon } \\
p \text {-Value }\end{array}$ \\
\hline Tumor site & & & $0.962^{\mathrm{a}}$ \\
\hline Limb & $45(45.0)$ & $35(47.9)$ & \\
\hline Trunk & $45(45.0)$ & $32(43.8)$ & \\
\hline Head/neck & $8(8.0)$ & $6(8.2)$ & \\
\hline Other & $2(2.0)$ & $0(0.0)$ & \\
\hline NAS & 0 & 1 & \\
\hline Histology & & & 0.565 \\
\hline $\begin{array}{c}\text { Superficial spreading } \\
\text { melanoma }\end{array}$ & $49(49.0)$ & $40(54.1)$ & \\
\hline Nodular melanoma & $36(36.0)$ & $21(28.4)$ & \\
\hline Other & $15(15.0)$ & $13(17.6)$ & \\
\hline Breslow thickness (mm) & & & 0.587 \\
\hline Mean (SD) & $6.0(5.3)$ & $5.6(4.6)$ & \\
\hline Median (Q1-Q3) & $4.3(3.0-6.5)$ & $4.0(3.0-6.0)$ & \\
\hline Min-Max & $2.1-35.0$ & $2.0-25.0$ & \\
\hline Mitotic rate & & & 0.0024 \\
\hline Mean (SD) & $9.4(9.1)$ & $5.9(4.5)$ & \\
\hline Median (Q1-Q3) & $8.0(3.0-11.0)$ & $5.0(3.0-7.0)$ & \\
\hline Min-Max & $0.0-57.0$ & $0.0-23.0$ & \\
\hline Clark level & & & 0.257 \\
\hline III & $8(8.1)$ & $2(2.7)$ & \\
\hline IV & $77(77.8)$ & $58(78.4)$ & \\
\hline $\mathrm{V}$ & $14(14.1)$ & $14(18.9)$ & \\
\hline Missing & 1 & 0 & \\
\hline Ulceration & & & 0.628 \\
\hline No & $29(29.0)$ & $19(25.7)$ & \\
\hline Yes & $71(71.0)$ & $55(74.3)$ & \\
\hline TILs & & & $<0.001$ \\
\hline Absent & $10(10.0)$ & $33(45.2)$ & \\
\hline Non brisk & $82(82.0)$ & $26(35.6)$ & \\
\hline Brisk & $8(8.0)$ & $14(19.2)$ & \\
\hline Missing & 0 & 1 & \\
\hline Stage at diagnosis & & & $<0.001^{b}$ \\
\hline I & $0(0.0)$ & $1(1.4)$ & \\
\hline IB & $0(0.0)$ & $1(1.4)$ & \\
\hline II & $58(58.0)$ & $62(83.8)$ & \\
\hline IIA & $12(20.7)$ & $10(13.5)$ & \\
\hline IIB & $23(39.7)$ & $32(43.2)$ & \\
\hline IIC & $23(39.7)$ & $20(27.0)$ & \\
\hline III & $42(42.0)$ & $10(13.5)$ & \\
\hline IIIA & $0(0.0)$ & $1(1.4)$ & \\
\hline IIIB & $7(16.7)$ & $1(1.4)$ & \\
\hline IIIC & $30(71.4)$ & $8(10.8)$ & \\
\hline IIID & $5(11.9)$ & $0(0.0)$ & \\
\hline IV & $0(0.0)$ & $1(1.4)$ & \\
\hline
\end{tabular}

${ }^{\mathrm{a}}$ The Other and NAS categories were not considered for the statistical test. ${ }^{\mathrm{b}}$ The comparison was performed considering only stage II and stage III patients. 
Table 2. Image analysis.

\begin{tabular}{|c|c|c|c|}
\hline Density & $\begin{array}{l}\text { Training Cohort } \\
\qquad N=100\end{array}$ & $\begin{array}{l}\text { Validation Cohort } \\
\qquad N=74\end{array}$ & $\begin{array}{c}\text { Chi-Squared or Wilcoxon } \\
p \text {-Value }\end{array}$ \\
\hline CD3+ & & & \\
\hline $\begin{array}{l}\text { Intratumoral density } \\
\left(\text { cells } / \mathrm{mm}^{2}\right)\end{array}$ & & & 0.360 \\
\hline Mean (SD) & $1543.9(1448.4)$ & $1202.7(1051.8)$ & \\
\hline Median (Q1-Q3) & $997.7(483.8-2163.5)$ & $800.9(451.2-1590.9)$ & \\
\hline Min-Max & $21.0-6275.8$ & $47.8-5694.4$ & \\
\hline Missing & 19 & 0 & \\
\hline $\begin{array}{l}\text { CD3+ intratumoral density } \\
\text { according to the median of } \\
\text { the training cohort }\end{array}$ & & & 0.453 \\
\hline Low & $40(49.4)$ & $41(55.4)$ & \\
\hline High & $41(50.6)$ & $33(44.6)$ & \\
\hline Missing & 19 & 0 & \\
\hline $\begin{array}{l}\text { CD3+ peritumoral IN } \\
\text { density (cells/mm²) }\end{array}$ & & & 0.014 \\
\hline Mean (SD) & $2281.1(1483.6)$ & $1765.0(1492.4)$ & \\
\hline Median (Q1-Q3) & $2146.9(1084.5-3162.3)$ & $1334.0(775.0-2334.8)$ & \\
\hline Min-Max & $61.4-6619.7$ & $0.0-8655.1$ & \\
\hline Missing & 11 & 3 & \\
\hline $\begin{array}{l}\text { CD3+ peritumoral IN } \\
\text { density according to the } \\
\text { median of the training } \\
\text { cohort }\end{array}$ & & & 0.021 \\
\hline Low & $44(49.4)$ & $48(67.6)$ & \\
\hline High & $45(50.6)$ & $23(32.4)$ & \\
\hline Missing & 11 & 3 & \\
\hline $\begin{array}{c}\text { CD3+ peritumoral OUT } \\
\left.\text { density (cells } / \mathrm{mm}^{2}\right)\end{array}$ & & & $<0.001$ \\
\hline Mean $(\mathrm{SD})$ & $1916.9(1363.2)$ & $379.5(335.5)$ & \\
\hline Median (Q1-Q3) & $1611.6(796.2-2810.5)$ & $263.3(146.3-483.5)$ & \\
\hline Min-Max & $84.6-5300.5$ & 27.6-1788.6 & \\
\hline Missing & 11 & 3 & \\
\hline $\begin{array}{l}\text { CD3+ peritumoral OUT } \\
\text { density according to the } \\
\text { median of the training } \\
\text { cohort }\end{array}$ & & & $<0.001$ \\
\hline Low & $44(49.4)$ & $70(98.6)$ & \\
\hline High & $45(50.6)$ & $1(1.4)$ & \\
\hline Missing & 11 & 3 & \\
\hline $\begin{array}{l}\text { CD4+ intratumoral density } \\
\left(\text { cells } / \mathrm{mm}^{2}\right)\end{array}$ & & & 0.340 \\
\hline Mean (SD) & $1675.2(1379.9)$ & $1532.3(1422.1)$ & \\
\hline Median (Q1-Q3) & $1421.9(649.5-2333.5)$ & $1224.8(551.6-2166.8)$ & \\
\hline Min-Max & $0.0-7304.6$ & $11.4-8665.0$ & \\
\hline Missing & 4 & & \\
\hline $\begin{array}{l}\text { CD4+ intratumoral density } \\
\text { according to the median of } \\
\text { the training cohort }\end{array}$ & & & 0.293 \\
\hline Low & $48(50.0)$ & $43(58.1)$ & \\
\hline High & $48(50.0)$ & $31(41.9)$ & \\
\hline Missing & 4 & 0 & \\
\hline $\begin{array}{l}\text { CD4+ peritumoral IN } \\
\text { density (cells/mm²) }\end{array}$ & & & 0.005 \\
\hline Mean (SD) & $2622.3(1662.8)$ & $1882.2(1247.8)$ & \\
\hline Median (Q1-Q3) & $2384.0(1264.5-3727.1)$ & $1714.5(854.8-2580.0)$ & \\
\hline Min-Max & $0.4-6760.9$ & $16.7-5601.2$ & \\
\hline Missing & 11 & 4 & \\
\hline
\end{tabular}


Table 2. Cont.

\begin{tabular}{|c|c|c|c|}
\hline Density & $\begin{array}{l}\text { Training Cohort } \\
\qquad N=100\end{array}$ & $\begin{array}{l}\text { Validation Cohort } \\
\qquad N=74\end{array}$ & $\begin{array}{c}\text { Chi-Squared or Wilcoxon } \\
p \text {-Value }\end{array}$ \\
\hline $\begin{array}{l}\text { CD4+ peritumoral IN } \\
\text { density according to the } \\
\text { median of the training } \\
\text { cohort }\end{array}$ & & & 0.005 \\
\hline Low & $44(49.4)$ & $50(71.4)$ & \\
\hline High & $45(50.6)$ & $20(28.6)$ & \\
\hline Missing & 11 & 4 & \\
\hline $\begin{array}{l}\text { CD4+ peritumoral OUT } \\
\left.\text { density (cells } / \mathrm{mm}^{2}\right)\end{array}$ & & & $<0.001$ \\
\hline Mean $(\mathrm{SD})$ & $2177.9(1467.5)$ & $601.4(440.3)$ & \\
\hline Median (Q1-Q3) & $1965.3(1058.0-3124.4)$ & $495.1(254.3-804.8)$ & \\
\hline Min-Max & $0.0-6137.5$ & $24.4-1979.4$ & \\
\hline Missing & 11 & 4 & \\
\hline $\begin{array}{l}\text { CD4+ peritumoral OUT } \\
\text { density according to the } \\
\text { median of the training } \\
\text { cohort }\end{array}$ & & & $<0.001$ \\
\hline Low & $44(49.4)$ & $69(98.6)$ & \\
\hline High & $45(50.6)$ & $1(1.4)$ & \\
\hline Missing & 11 & 4 & \\
\hline $\begin{array}{c}\text { CD8+ intratumoral density } \\
\left(\text { cells } / \mathrm{mm}^{2}\right)\end{array}$ & & & 0.823 \\
\hline Mean (SD) & $868.8(1028.3)$ & $751.4(719.6)$ & \\
\hline Median (Q1-Q3) & $553.8(160.7-1181.2)$ & $441.9(258.1-1187.4)$ & \\
\hline Min-Max & $13.1-6559.4$ & $32.0-3809.9$ & \\
\hline MIssing & 5 & 0 & \\
\hline $\begin{array}{l}\text { CD8+ intratumoral density } \\
\text { according to the median of } \\
\text { the training cohort }\end{array}$ & & & 0.142 \\
\hline Low & $47(49.5)$ & $45(60.8)$ & \\
\hline High & $48(50.5)$ & $29(39.2)$ & \\
\hline Missing & 5 & 0 & \\
\hline $\begin{array}{l}\text { CD8+ peritumoral IN } \\
\text { density (cells/mm²) }\end{array}$ & & & 0.090 \\
\hline Mean (SD) & $1429.1(1335.5)$ & $1054.4(1062.0)$ & \\
\hline Median (Q1-Q3) & $1032.2(447.1-2266.7)$ & $654.9(320.8-1398.9)$ & \\
\hline Min-Max & $33.2-5911.3$ & $17.6-5334.9$ & \\
\hline Missing & 11 & 3 & \\
\hline $\begin{array}{l}\text { CD8+ peritumoral IN } \\
\text { density according to the } \\
\text { median of the training } \\
\text { cohort }\end{array}$ & & & 0.034 \\
\hline Low & $44(49.4)$ & $47(66.2)$ & \\
\hline High & $45(50.6)$ & $24(33.8)$ & \\
\hline Missing & 11 & 3 & \\
\hline $\begin{array}{c}\text { CD8+ peritumoral OUT } \\
\left.\text { density (cells } / \mathrm{mm}^{2}\right)\end{array}$ & & & $<0.001$ \\
\hline Mean (SD) & $1119.8(1122.1)$ & $227.0(287.3)$ & \\
\hline Median (Q1-Q3) & $646.2(358.1-1406.7)$ & $154.5(80.0-231.5)$ & \\
\hline Min-Max & $4.8-5088.9$ & $5.3-1651.2$ & \\
\hline Missing & 11 & 3 & \\
\hline $\begin{array}{l}\text { CD8+ peritumoral OUT } \\
\text { density according to the } \\
\text { median of the training } \\
\text { cohort }\end{array}$ & & & $<0.001$ \\
\hline Low & $44(49.4)$ & $67(94.4)$ & \\
\hline High & $45(50.6)$ & $4(5.6)$ & \\
\hline Missing & 11 & 3 & \\
\hline
\end{tabular}


Table 2. Cont

\begin{tabular}{|c|c|c|c|}
\hline Density & $\begin{array}{l}\text { Training Cohort } \\
\qquad N=100\end{array}$ & $\begin{array}{c}\text { Validation Cohort } \\
\qquad N=74\end{array}$ & $\begin{array}{c}\text { Chi-Squared or Wilcoxon } \\
p \text {-Value }\end{array}$ \\
\hline $\begin{array}{c}\text { CD68+ intratumoral density } \\
\left(\text { cells } / \mathrm{mm}^{2}\right)\end{array}$ & & & 0.015 \\
\hline Mean (SD) & $367.2(398.5)$ & $583.7(633.1)$ & \\
\hline Median (Q1-Q3) & $248.1(95.6-488.8)$ & $363.8(172.6-763.1)$ & \\
\hline Min-Max & $4.8-1981.5$ & $1.7-2958.6$ & \\
\hline Missing & 6 & 0 & \\
\hline $\begin{array}{l}\text { CD68+ intratumoral density } \\
\text { according to the median of } \\
\text { the training cohort }\end{array}$ & & & 0.296 \\
\hline Low & $47(50.0)$ & $31(41.9)$ & \\
\hline High & $47(50.0)$ & $43(58.1)$ & \\
\hline Missing & 6 & 0 & \\
\hline $\begin{array}{l}\text { CD68+ peritumoral IN } \\
\text { density (cells } / \mathrm{mm}^{2} \text { ) }\end{array}$ & & & 0.281 \\
\hline Mean $(\mathrm{SD})$ & $469.7(494.6)$ & $611.7(658.4)$ & \\
\hline Median (Q1-Q3) & $264.3(128.9-661.9)$ & $459.7(144.1-773.6)$ & \\
\hline Min-Max & $0.0-2589.4$ & $1.3-3022.2$ & \\
\hline Missing & 11 & 3 & \\
\hline $\begin{array}{l}\text { CD68+ peritumoral IN } \\
\text { density according to the } \\
\text { median of the training } \\
\text { cohort }\end{array}$ & & & 0.104 \\
\hline Low & $44(49.4)$ & $26(36.6)$ & \\
\hline High & $45(50.6)$ & $45(63.4)$ & \\
\hline Missing & 11 & 3 & \\
\hline $\begin{array}{l}\text { CD68+ peritumoral OUT } \\
\text { density (cells } / \mathrm{mm}^{2} \text { ) }\end{array}$ & & & $<0.001$ \\
\hline Mean (SD) & $337.9(312.6)$ & $88.7(120.3)$ & \\
\hline Median (Q1-Q3) & $243.4(116.7-476.0)$ & $51.9(5.9-136.7)$ & \\
\hline Min-Max & 2.9-1775.6 & $0.0-588.2$ & \\
\hline Missing & 11 & 3 & \\
\hline $\begin{array}{l}\text { CD68+ peritumoral OUT } \\
\text { density according to the } \\
\text { median of the training } \\
\text { cohort }\end{array}$ & & & $<0.001$ \\
\hline Low & $45(50.6)$ & $67(94.4)$ & \\
\hline High & $44(49.4)$ & $4(5.6)$ & \\
\hline Missing & 11 & 3 & \\
\hline $\begin{array}{l}\text { CD163+ intratumoral } \\
\text { density (cells } / \mathrm{mm}^{2} \text { ) }\end{array}$ & & & - \\
\hline Mean (SD) & $1188.9(1073.4)$ & - & \\
\hline Median (Q1-Q3) & $757.6(481.2-1580.8)$ & - & \\
\hline Min-Max & $18.8-5017.9$ & - & \\
\hline Missing & 4 & - & \\
\hline $\begin{array}{l}\text { CD163+ peritumoral IN } \\
\text { density (cells } / \mathrm{mm}^{2} \text { ) }\end{array}$ & & & - \\
\hline Mean (SD) & $1472.6(1090.4)$ & - & \\
\hline Median (Q1-Q3) & $1205.6(608.6-2033.9)$ & - & \\
\hline Min-Max & $41.4-5147.3$ & - & \\
\hline Missing & 11 & - & \\
\hline $\begin{array}{l}\text { CD163+ peritumoral OUT } \\
\text { density }\left(\text { cells } / \mathrm{mm}^{2}\right)\end{array}$ & & & - \\
\hline Mean (SD) & $1061.4(691.7)$ & - & \\
\hline Median (Q1-Q3) & 878.3 (548.9-1388.2) & - & \\
\hline Min-Max & $101.4-3456.6$ & - & \\
\hline Missing & 11 & - & \\
\hline
\end{tabular}


Table 2. Cont

\begin{tabular}{|c|c|c|c|}
\hline Density & $\begin{array}{l}\text { Training Cohort } \\
\qquad N=100\end{array}$ & $\begin{array}{l}\text { Validation Cohort } \\
\qquad \mathrm{N}=74\end{array}$ & $\begin{array}{c}\text { Chi-Squared or Wilcoxon } \\
\qquad \text {-Value }\end{array}$ \\
\hline $\begin{array}{c}\text { FOXP3 intratumoral density } \\
\left(\text { cells } / \mathrm{mm}^{2}\right)\end{array}$ & & & - \\
\hline Mean $(\mathrm{SD})$ & 528.5 (1297.7) & - & \\
\hline Median (Q1-Q3) & $40.5(2.2-315.3)$ & - & \\
\hline Min-Max & $0.0-6794.9$ & - & \\
\hline Missing & 4 & - & \\
\hline $\begin{array}{l}\text { FOXP3 peritumoral IN } \\
\left.\text { density (cells } / \mathrm{mm}^{2}\right)\end{array}$ & & & - \\
\hline Mean (SD) & $430.1(1031.0)$ & - & \\
\hline Median (Q1-Q3) & $69.2(1.5-409.2)$ & - & \\
\hline Min-Max & $0.0-7104.4$ & - & \\
\hline Missing & 11 & - & \\
\hline $\begin{array}{l}\text { FOXP3 peritumoral OUT } \\
\text { density }\left(\text { cells } / \mathrm{mm}^{2}\right)\end{array}$ & & & - \\
\hline Mean (SD) & $292.4(602.4)$ & - & \\
\hline Median (Q1-Q3) & $40.3(0.5-306.1)$ & - & \\
\hline Min-Max & $0.0-2898.8$ & - & \\
\hline Missing & 11 & - & \\
\hline $\begin{array}{l}\text { PD1 intratumoral density } \\
\left(\text { cells } / \mathrm{mm}^{2}\right)\end{array}$ & & & - \\
\hline Mean $(\mathrm{SD})$ & $440.4(604.6)$ & - & \\
\hline Median (Q1-Q3) & $253.5(57.9-507.5)$ & - & \\
\hline Min-Max & $3.7-3038.4$ & - & \\
\hline Missing & 4 & - & \\
\hline $\begin{array}{l}\text { PD1 peritumoral IN density } \\
\left(\text { cells } / \mathrm{mm}^{2}\right)\end{array}$ & & & - \\
\hline Mean (SD) & $806.4(959.3)$ & - & \\
\hline Median (Q1-Q3) & $512.3(164.9-1124.6)$ & - & \\
\hline Min-Max & $7.2-5068.7$ & - & \\
\hline Missing & 11 & - & \\
\hline $\begin{array}{l}\text { PD1 peritumoral OUT } \\
\text { density (cells } / \mathrm{mm}^{2} \text { ) }\end{array}$ & & & - \\
\hline Mean $(\mathrm{SD})$ & $549.9(678.0)$ & - & \\
\hline Median (Q1-Q3) & $361.4(160.9-654.2)$ & - & \\
\hline Min-Max & $6.2-4411.1$ & - & \\
\hline Missing & 11 & - & \\
\hline $\begin{array}{l}\text { PD-L1 intratumoral density } \\
\left(\text { cells } / \mathrm{mm}^{2}\right)\end{array}$ & & & - \\
\hline Mean (SD) & $358.5(872.7)$ & - & \\
\hline Median (Q1-Q3) & $39.9(11.9-260.2)$ & - & \\
\hline Min-Max & $0.1-6251.2$ & - & \\
\hline Missing & 4 & - & \\
\hline $\begin{array}{l}\text { PD-L1 peritumoral IN } \\
\text { density }\left(\text { cells } / \mathrm{mm}^{2}\right)\end{array}$ & & & - \\
\hline Mean (SD) & $331.3(685.1)$ & - & \\
\hline Median (Q1-Q3) & $52.0(8.8-257.5)$ & - & \\
\hline Min-Max & $0.0-3501.0$ & - & \\
\hline Missing & 11 & - & \\
\hline $\begin{array}{l}\text { PD-L1 peritumoral OUT } \\
\left.\text { density (cells } / \mathrm{mm}^{2}\right)\end{array}$ & & & - \\
\hline Mean (SD) & $108.0(192.5)$ & - & \\
\hline Median (Q1-Q3) & $30.1(9.4-124.0)$ & - & \\
\hline Min-Max & $0.0-919.1$ & - & \\
\hline Missing & 11 & - & \\
\hline
\end{tabular}

When comparing the three different regions (Table S3), we observed some striking spatial differences. A statistically significant higher density was found in the inner per- 
itumoral area for $\mathrm{CD}^{+}(p=0.001), \mathrm{CD}^{+}(p<0.001)$, and $\mathrm{CD}^{+}(p=0.002)$ as compared to the intratumoral area and for $\mathrm{CD}^{+}(p=0.035)$ and $\mathrm{CD}^{+} 63^{+}(p=0.003)$ compared to the outer peritumoral area (Figure S1). A longer DFS was statistically associated with higher levels of $\mathrm{CD}^{+}$intratumoral T-cells (aHR [100 cell/ $\mathrm{mm}^{2}$ increase] $0.98,95 \% \mathrm{CI}$ $0.95-1.00, p=0.041$ ) and $\mathrm{CD}_{163}{ }^{+}$inner peritumoral (aHR[high vs. low] $0.56,95 \% \mathrm{CI} 0.32$ $0.99, p=0.047$ ) (Table 3). A statistically positive impact on OS was found for higher levels of $\mathrm{CD}^{+}$outer peritumoral T-cells (aHR[100 cell $/ \mathrm{mm}^{2}$ increase] $0.98,95 \% \mathrm{CI} 0.95-1.00$, $p=0.044$ ) and $\mathrm{CD}^{+} 8^{+}$intratumoral macrophages (aHR[100 cell $/ \mathrm{mm}^{2}$ increase $] 0.52,95 \% \mathrm{CI}$ $0.29-0.95, p=0.033$ ) (Table 3).

Table 3. Effect of biomarkers density on disease free survival and overall survival in the training cohort. Univariable and multivariable Cox proportional hazard models.

\begin{tabular}{|c|c|c|c|c|c|c|c|c|}
\hline & \multicolumn{4}{|c|}{ DISEASE FREE SURVIVAL } & \multicolumn{4}{|c|}{ OVERALL SURVIVAL } \\
\hline & \multicolumn{2}{|c|}{ Univariable Analysis } & \multicolumn{2}{|c|}{ Multivariable Analysis } & \multicolumn{2}{|c|}{ Univariable Analysis } & \multicolumn{2}{|c|}{ Multivariable Analysis } \\
\hline & HR $(95 \%$ CI) & $\begin{array}{c}p- \\
\text { Value }\end{array}$ & HR $(95 \%$ CI) & $\begin{array}{c}p- \\
\text { Value }\end{array}$ & HR $(95 \%$ CI) & $\begin{array}{c}p- \\
\text { Value }\end{array}$ & HR $(95 \%$ CI) & $\begin{array}{c}p- \\
\text { Value }\end{array}$ \\
\hline \multicolumn{9}{|l|}{ CD3+ } \\
\hline Intratumoral (100 cell/mm2 increase) & $0.98(0.96-1.00)$ & 0.060 & $0.98(0.96-1.00)$ & 0.059 & $0.98(0.96-1.00)$ & 0.121 & $0.98(0.96-1.00)$ & 0.074 \\
\hline Intratumoral (high vs. low) & $0.59(0.35-1.00)$ & $\underset{*}{0.050}$ & $0.59(0.33-1.05)$ & 0.072 & $0.72(0.41-1.27)$ & 0.256 & $0.66(0.36-1.20)$ & 0.173 \\
\hline Peritumoral IN (100 cell/mm2 increase) & $0.98(0.96-1.00)$ & 0.072 & $0.98(0.97-1.00)$ & 0.090 & $0.98(0.96-1.00)$ & 0.112 & $0.99(0.96-1.01)$ & 0.179 \\
\hline Peritumoral IN (high vs. low) & $0.75(0.44-1.28)$ & 0.290 & $0.78(0.46-1.33)$ & 0.361 & $0.75(0.42-1.34)$ & 0.338 & $0.76(0.43-1.37)$ & 0.365 \\
\hline Peritumoral OUT (100 cell/mm2 increase) & $0.98(0.96-1.00)$ & 0.120 & $0.98(0.96-1.00)$ & 0.055 & $0.98(0.96-1.01)$ & 0.183 & $0.98(0.95-1.00)$ & $\underset{*}{0.044}$ \\
\hline Peritumoral OUT (high vs. low) & $0.69(0.40-1.18)$ & 0.172 & $0.62(0.36-1.07)$ & 0.086 & $0.80(0.45-1.44)$ & 0.459 & $0.64(0.35-1.15)$ & 0.137 \\
\hline \multicolumn{9}{|l|}{ CD4+ } \\
\hline Intratumoral (100 cell/mm2 increase) & $0.98(0.95-1.00)$ & $\underset{*}{0.032}$ & $0.98(0.95-1.00)$ & $\underset{*}{0.041}$ & $0.98(0.95-1.00)$ & 0.073 & $0.98(0.95-1.00)$ & 0.104 \\
\hline Intratumoral (high vs. low) & $0.67(0.41-1.09)$ & 0.109 & $0.70(0.43-1.16)$ & 0.166 & $0.67(0.39-1.17)$ & 0.159 & $0.75(0.43-1.31)$ & 0.318 \\
\hline Peritumoral IN (100 cell/mm2 increase) & $0.98(0.96-1.00)$ & 0.056 & $0.99(0.97-1.01)$ & 0.196 & $0.98(0.96-1.00)$ & 0.086 & $0.99(0.97-1.01)$ & 0.296 \\
\hline Peritumoral IN (high vs. low) & $0.71(0.42-1.20)$ & 0.201 & $0.83(0.48-1.44)$ & 0.510 & $0.79(0.45-1.41)$ & 0.434 & $0.97(0.54-1.75)$ & 0.925 \\
\hline Peritumoral OUT (100 cell/mm2 increase) & $0.98(0.97-1.00)$ & 0.123 & $0.98(0.96-1.00)$ & 0.096 & $0.99(0.97-1.01)$ & 0.412 & $0.98(0.96-1.01)$ & 0.175 \\
\hline Peritumoral OUT (high vs. low) & $0.74(0.44-1.26)$ & 0.270 & $0.70(0.40-1.22)$ & 0.210 & $0.80(0.45-1.42)$ & 0.443 & $0.64(0.35-1.18)$ & 0.153 \\
\hline \multicolumn{9}{|l|}{ CD8+ } \\
\hline Intratumoral $(100 \mathrm{cell} / \mathrm{mm} 2$ increase $)$ & $0.98(0.95-1.01)$ & 0.108 & $0.99(0.96-1.02)$ & 0.387 & $0.96(0.92-1.00)$ & $\underset{*}{0.050}$ & $0.98(0.94-1.01)$ & 0.219 \\
\hline Intratumoral (high vs. low) & $0.70(0.42-1.15)$ & 0.160 & $0.74(0.45-1.22)$ & 0.241 & $0.57(0.32-0.99)$ & $\underset{*}{0.048}$ & $0.64(0.36-1.13)$ & 0.122 \\
\hline Peritumoral IN (100 cell/mm2 increase) & $0.99(0.97-1.01)$ & 0.287 & $1.00(0.97-1.02)$ & 0.693 & $0.98(0.95-1.01)$ & 0.112 & $0.99(0.96-1.02)$ & 0.451 \\
\hline Peritumoral IN (high vs. low) & $0.90(0.53-1.52)$ & 0.684 & $1.05(0.60-1.81)$ & 0.872 & $0.73(0.41-1.31)$ & 0.293 & $0.87(0.47-1.60)$ & 0.657 \\
\hline Peritumoral OUT (100 cell/mm2 increase) & $0.98(0.95-1.01)$ & 0.157 & $0.98(0.95-1.01)$ & 0.171 & $0.98(0.94-1.01)$ & 0.152 & $0.97(0.94-1.01)$ & 0.151 \\
\hline Peritumoral OUT (high vs. low) & $0.95(0.56-1.62)$ & 0.853 & $0.98(0.57-1.69)$ & 0.947 & $0.75(0.42-1.35)$ & 0.336 & $0.74(0.41-1.35)$ & 0.323 \\
\hline \multicolumn{9}{|l|}{ CD68+ } \\
\hline Intratumoral (100 cell/mm2 increase) & $1.00(0.99-1.01)$ & 0.775 & $1.00(0.99-1.01)$ & 0.934 & $1.00(0.99-1.00)$ & 0.322 & $1.00(0.99-1.00)$ & 0.328 \\
\hline Intratumoral (high vs. low) & $0.86(0.52-1.42)$ & 0.547 & $0.78(0.46-1.31)$ & 0.349 & $0.51(0.29-0.92)$ & $\underset{*}{0.025}$ & $0.52(0.29-0.95)$ & $\underset{*}{0.033}$ \\
\hline Peritumoral IN (100 cell/mm2 increase) & $1.00(0.99-1.00)$ & 0.366 & $1.00(0.99-1.00)$ & 0.553 & $1.00(0.99-1.00)$ & 0.429 & $1.00(0.99-1.01)$ & 0.588 \\
\hline Peritumoral IN (high vs. low) & $0.83(0.48-1.40)$ & 0.478 & $0.79(0.46-1.37)$ & 0.408 & $0.75(0.42-1.36)$ & 0.345 & $0.73(0.40-1.32)$ & 0.298 \\
\hline Peritumoral OUT (100 cell/mm2 increase) & $1.00(1.00-1.01)$ & 0.451 & $1.00(1.00-1.01)$ & 0.368 & $1.00(0.99-1.01)$ & 0.862 & $1.00(0.99-1.01)$ & 0.864 \\
\hline Peritumoral OUT (high vs. low) & $1.10(0.65-1.86)$ & 0.725 & $1.02(0.58-1.79)$ & 0.945 & $0.85(0.47-1.51)$ & 0.574 & $0.70(0.38-1.30)$ & 0.259 \\
\hline \multicolumn{9}{|l|}{ CD163+ } \\
\hline Intratumoral (100 cell/mm2 increase) & $0.97(0.95-1.00)$ & $\underset{*}{0.046}$ & $0.98(0.96-1.00)$ & 0.070 & $0.97(0.95-1.00)$ & 0.062 & $0.98(0.95-1.00)$ & 0.094 \\
\hline Intratumoral (high vs. low) & $0.68(0.41-1.13)$ & 0.135 & $0.85(0.51-1.44)$ & 0.548 & $0.59(0.33-1.03)$ & 0.063 & $0.77(0.43-1.39)$ & 0.387 \\
\hline Peritumoral IN (100 cell/mm2 increase) & $0.98(0.95-1.00)$ & 0.093 & $0.98(0.96-1.01)$ & 0.127 & $0.98(0.95-1.01)$ & 0.170 & $0.99(0.96-1.01)$ & 0.275 \\
\hline Peritumoral IN (high vs. low) & $0.53(0.31-0.90)$ & $\underset{*}{0.019}$ & $0.56(0.32-0.99)$ & $\underset{*}{0.047}$ & $0.57(0.32-1.03)$ & 0.064 & $0.64(0.35-1.19)$ & 0.158 \\
\hline Peritumoral OUT (100 cell/mm2 increase) & $0.97(0.93-1.01)$ & 0.198 & $0.97(0.93-1.01)$ & 0.123 & $0.98(0.94-1.03)$ & 0.393 & $0.97(0.94-1.01)$ & 0.206 \\
\hline Peritumoral OUT (high vs. low) & $0.69(0.41-1.18)$ & 0.174 & $0.73(0.43-1.25)$ & 0.248 & $0.70(0.39-1.26)$ & 0.236 & $0.70(0.39-1.26)$ & 0.231 \\
\hline
\end{tabular}


Table 3. Cont

\begin{tabular}{|c|c|c|c|c|c|c|c|c|}
\hline & \multicolumn{4}{|c|}{ DISEASE FREE SURVIVAL } & \multicolumn{4}{|c|}{ OVERALL SURVIVAL } \\
\hline & \multicolumn{2}{|c|}{ Univariable Analysis } & \multicolumn{2}{|c|}{ Multivariable Analysis } & \multicolumn{2}{|c|}{ Univariable Analysis } & \multicolumn{2}{|c|}{ Multivariable Analysis } \\
\hline & HR $(95 \%$ CI) & $\begin{array}{c}p- \\
\text { Value }\end{array}$ & $\operatorname{HR}(95 \% \mathrm{CI})$ & $\begin{array}{c}p- \\
\text { Value }\end{array}$ & $\operatorname{HR}(95 \% \mathrm{CI})$ & $\begin{array}{c}p- \\
\text { Value }\end{array}$ & $\operatorname{HR}(95 \% \mathrm{CI})$ & $\begin{array}{c}p- \\
\text { Value }\end{array}$ \\
\hline \multicolumn{9}{|l|}{ FOXP3 } \\
\hline Intratumoral (10 cell/mm2 increase) & $1.00(1.00-1.00)$ & 0.359 & $1.00(1.00-1.00)$ & 0.804 & $1.00(1.00-1.00)$ & 0.050 & $1.00(1.00-1.00)$ & 0.329 \\
\hline Intratumoral (high vs. low) & $0.84(0.51-1.38)$ & 0.498 & $0.66(0.39-1.10)$ & 0.112 & $1.25(0.72-2.16)$ & 0.432 & $0.94(0.53-1.66)$ & 0.827 \\
\hline Peritumoral IN (10 cell/mm2 increase) & $1.00(1.00-1.00)$ & 0.713 & $1.00(1.00-1.00)$ & 0.377 & $1.00(1.00-1.00)$ & 0.565 & $1.00(1.00-1.00)$ & 0.956 \\
\hline Peritumoral IN (high vs. low) & $0.72(0.42-1.21)$ & 0.216 & $0.59(0.34-1.02)$ & 0.057 & $0.81(0.46-1.44)$ & 0.477 & $0.63(0.35-1.14)$ & 0.126 \\
\hline Peritumoral OUT (10 cell/mm2 increase) & $1.00(0.99-1.00)$ & 0.365 & $1.00(0.99-1.00)$ & 0.126 & $1.00(1.00-1.00)$ & 0.950 & $1.00(0.99-1.00)$ & 0.295 \\
\hline Peritumoral OUT (high vs. low) & $0.80(0.47-1.35)$ & 0.401 & $0.66(0.39-1.13)$ & 0.130 & $0.87(0.49-1.55)$ & 0.642 & $0.61(0.34-1.12)$ & 0.109 \\
\hline \multicolumn{9}{|l|}{ PD1 } \\
\hline Intratumoral (100 cell/mm2 increase) & $0.98(0.93-1.02)$ & 0.287 & $1.00(0.95-1.05)$ & 0.916 & $0.97(0.91-1.02)$ & 0.227 & $1.00(0.94-1.06)$ & 0.893 \\
\hline Intratumoral (high vs. low) & $0.84(0.51-1.38)$ & 0.492 & $0.96(0.57-1.62)$ & 0.878 & $0.58(0.33-1.03)$ & 0.061 & $0.63(0.35-1.12)$ & 0.117 \\
\hline Peritumoral IN (100 cell/mm2 increase) & $0.97(0.94-1.01)$ & 0.116 & $0.98(0.95-1.02)$ & 0.308 & $0.97(0.93-1.01)$ & 0.116 & $0.98(0.94-1.02)$ & 0.376 \\
\hline Peritumoral IN (high vs. low) & $0.62(0.36-1.06)$ & 0.078 & $0.70(0.40-1.22)$ & 0.210 & $0.53(0.29-0.97)$ & $\underset{*}{0.039}$ & $0.59(0.32-1.10)$ & 0.095 \\
\hline Peritumoral OUT (100 cell/mm2 increase) & $0.97(0.93-1.02)$ & 0.262 & $0.98(0.94-1.03)$ & 0.447 & $0.97(0.92-1.02)$ & 0.259 & $0.97(0.92-1.03)$ & 0.305 \\
\hline Peritumoral OUT (high vs. low) & $0.92(0.54-1.55)$ & 0.747 & $1.04(0.59-1.82)$ & 0.894 & $0.80(0.45-1.43)$ & 0.456 & $0.86(0.47-1.59)$ & 0.638 \\
\hline \multicolumn{9}{|l|}{ PD-L1 } \\
\hline Intratumoral (10 cell/mm2 increase) & $1.00(1.00-1.00)$ & 0.764 & $1.00(1.00-1.00)$ & 0.823 & $1.00(1.00-1.00)$ & 0.847 & $1.00(1.00-1.00)$ & 0.624 \\
\hline Intratumoral (high vs. low) & $0.90(0.54-1.49)$ & 0.678 & $1.03(0.62-1.74)$ & 0.897 & $0.83(0.47-1.46)$ & 0.514 & $0.98(0.55-1.75)$ & 0.957 \\
\hline Peritumoral IN (10 cell/mm2 increase) & $0.99(0.99-1.00)$ & 0.069 & $1.00(0.99-1.00)$ & 0.128 & $0.99(0.98-1.00)$ & 0.085 & $0.99(0.99-1.00)$ & 0.154 \\
\hline Peritumoral IN (high vs. low) & $0.70(0.41-1.19)$ & 0.188 & $0.76(0.44-1.31)$ & 0.327 & $0.51(0.28-0.93)$ & $\begin{array}{l}0.027 \\
*\end{array}$ & $0.58(0.31-1.07)$ & 0.079 \\
\hline Peritumoral OUT (10 cell/mm2 increase) & $0.99(0.97-1.00)$ & 0.123 & $0.98(0.97-1.00)$ & 0.098 & $0.99(0.97-1.01)$ & 0.241 & $0.98(0.96-1.00)$ & 0.128 \\
\hline Peritumoral OUT (high vs. low) & $0.94(0.55-1.61)$ & 0.830 & $0.92(0.53-1.60)$ & 0.772 & $0.94(0.52-1.69)$ & 0.839 & $0.80(0.44-1.46)$ & 0.461 \\
\hline
\end{tabular}

Note. Multivariable models adjusted for Breslow thickness, ulceration and stage. * Significant $p$-value at 0.05 level.

Figure 2 and Figure S2 summarize the analysis of the prognostic impact of the combination of the density and distribution of $\mathrm{CD} 8^{+} \mathrm{T}$-cells with the density and distribution of other immune cells in the tumor microenvironment. A statistically significant longer DFS (aHR[high-high vs. low-low] 0.52, 95\%CI 0.28-0.99, $p=0.047$ ) and OS (aHR[high-high vs. low-low] $0.39,95 \%$ CI $0.18-0.85, p=0.018$ ) was found in patients with a high density of both intratumoral CD8+ T-cells and $\mathrm{CD} 68^{+}$macrophages as compared to those with a low density of both intratumoral CD8+ T-cells and $\mathrm{CD} 68^{+}$macrophages.

\subsection{Validation Cohort}

Overall, 74 stage melanoma patients with $\mathrm{BT} \geq 2 \mathrm{~mm}$ were included in the validation cohort. Data on $\mathrm{CD}^{+}, \mathrm{CD}^{+}, \mathrm{CD}^{+}$, and $\mathrm{CD} 68^{+}$image analysis were available. Tables 1 and 2 show a comparison between the training cohort and the validation cohort in terms of demographical and clinical characteristics and distribution of immune cells. Tables S4 and S5 show the correlation between the density and spatial distribution of immune cells as well as their correlation with BT in the validation cohort. The median followup was 161.6 months (IQR 126.7-201.0). Overall, 39 patients (52.7\%) relapsed, 37 patients (50.0\%) died, and 41 patients (55.4\%) relapsed or/and died (i.e., DFS events). The median DFS and OS were 88.3 months (IQR 14.7-301.1) and 140.8 months (IQR 36.1-301.1), respectively.

In line with data obtained in the training cohort, a statistically significant higher density was found in the inner peritumoral area when compared to the intratumoral density for $\mathrm{CD}^{+}(p=0.0101)$ and $\mathrm{CD}^{+}(p=0.0473)$ but not for $\mathrm{CD} 4^{+}$. Moreover, for all the markers a statistically significant lower density was detected in the outer peritumoral area (Table S3). 
A

Intratumoral CD3 CD8 High-low
Low-High

Intratumoral CD4 CD8

High-low
Low-High

High-High
Intratumoral CD68 CD8

High-low

High-High
tratumoral PD-L1 CD

High-low

High-High
Peritumoral IN CD3 CD8

High-low
Low-High

High-High
Peritumoral IN CD4 CD8

High-low

Low-High

Peritumoral IN CD68 CD8

High-low

High-High
Peritumoral IN PD-L1 CD8

High-low
Low-High

High-High

( DD3 CD8

High-low
Low-High

High-High
Peritumoral OUT CD4 CD8

High-low

Peritumoral OUT CD68 CD8

High-low

High-High
Peritumoral OUT PD-L1 CD8

High-low

Low-High
High-High

B

\begin{tabular}{|c|}
\hline $\begin{array}{l}\text { Intratumoral CD3 CD8 } \\
\text { High-low } \\
\text { Low-High } \\
\text { High-High } \\
\text { Intratumoral CD4 CD8 } \\
\text { High-low } \\
\text { Low-High } \\
\text { High-High } \\
\text { Intratumoral CD68 CD8 } \\
\text { High-low } \\
\text { Low-High } \\
\text { High-High } \\
\text { Intratumoral PD-L1 CD8 } \\
\text { High-low } \\
\text { Low-High } \\
\text { High-High } \\
\text { Peritumoral IN CD3 CD8 } \\
\text { High-low } \\
\text { Low-High } \\
\text { High-High } \\
\text { Peritumoral IN CD4 CD8 } \\
\text { High-low } \\
\text { Low-High } \\
\text { High-High } \\
\text { Peritumoral IN CD68 CD8 } \\
\text { High-low } \\
\text { Low-High } \\
\text { High-High } \\
\text { Peritumoral IN PD-L1 CD8 } \\
\text { High-low } \\
\text { Low-High } \\
\text { High-High } \\
\text { Peritumoral OUT CD3 CD8 } \\
\text { High-low } \\
\text { Low-High } \\
\text { High-High } \\
\text { Peritum-oral OUT CD4 CD8 } \\
\text { High-low } \\
\text { Low-High } \\
\text { High-High } \\
\text { Peritumoral OUT CD68 CD8 } \\
\text { High-low } \\
\text { Low-High } \\
\text { High-High } \\
\text { Peritumoral OUT PD-L1 CD8 } \\
\text { High-low } \\
\text { Low-High } \\
\text { High-High }\end{array}$ \\
\hline
\end{tabular}

Adjusted HR [95\%Cl]

$(95 \% \mathrm{Cl}), \mathrm{p}$-value patients events

Reference: Low-low $0.82(0.33-2.00), 0.658$ $0.52(0.28-0.99), 0.047^{\star}$ $0.50(0.20-1.25), 0.138$ $0.57(0.25-1.30), 0.181$
$0.64(0.36-1.13), 0.126$ Reference: Low-low
$0.70(0.32-1.49), 0.350$ $0.62(0.30-1.26), 0.187$ $0.59(0.30-1.16), 0.129$ Reference: Low-low
$1.43(0.63-3.27), 0.392$ $0.76(0.36-1.60), 0.469$ Reference: Low-low
$0.57(0.21-1.54) 0.271$ $0.57(0.21-1.54), 0.271$
$1.24(0.48-3.20), 0.655$ $0.89(0.49-1.62), 0.709$ Reference: Low-low
$0.87(0.35-2.15), 0.765$ $1.43(0.60-3.41), 0.425$ Reference: Low-low $0.89(0.40-2.01), 0.782$ $1.31(0.62-2.80), 0.480$ Reference: Low-low $0.83(0.35-1.97), 0.675$
$0.49(0.68-3.26), 0.322$ $0.84(0.44-1.61), 0.608$ Reference: Low-low
$0.58(0.21-1.58), 0.288$ $1.63(0.71-3.73), 0.250$
$0.73(0.39-1.36), 0.317$ Reference: Low-low
$0.71(0.31-1.65), 0.42$ $1.23(0.56-2.73), 0.602$ $0.75(0.39-1.47), 0.409$ Reference: Low-low
$0.87(0.38-1.96), 0.733$ $0.83(0.37-1.84), 0.640$
$1.01(0.51-2.02), 0.968$ $1.03(0.46-2.33), 0.938$
$1.12(0.52-2.41), 0.765$ $1.12(0.52-2.41), 0.765$
$0.92(0.47-1.81), 0.803$

$\begin{array}{ll}31 & 23 \\ 10 & 7 \\ 8 & 7 \\ 31 & 20 \\ 35 & 26 \\ 12 & 6 \\ 12 & 8 \\ 36 & 24 \\ 26 & 20 \\ 19 & 11 \\ 20 & 14 \\ 28 & 18 \\ 34 & 24 \\ 13 & 8 \\ 14 & 11 \\ 34 & 21 \\ 36 & 26 \\ 8 & 5 \\ 8 & 6 \\ 37 & 21 \\ 34 & 25 \\ 10 & 6 \\ 10 & 8 \\ 35 & 19 \\ 30 & 22 \\ 14 & 9 \\ 14 & 11 \\ 31 & 16 \\ 32 & 24 \\ 12 & 7 \\ 12 & 9 \\ 33 & 18 \\ 34 & 26 \\ 10 & 5 \\ 10 & 8 \\ 35 & 19 \\ 31 & 23 \\ 13 & 8 \\ 13 & 10 \\ 32 & 17 \\ 30 & 22 \\ 14 & 9 \\ 15 & 9 \\ 30 & 18 \\ 30 & 22 \\ 14 & 9 \\ 15 & 10 \\ 30 & 17 \\ & \end{array}$

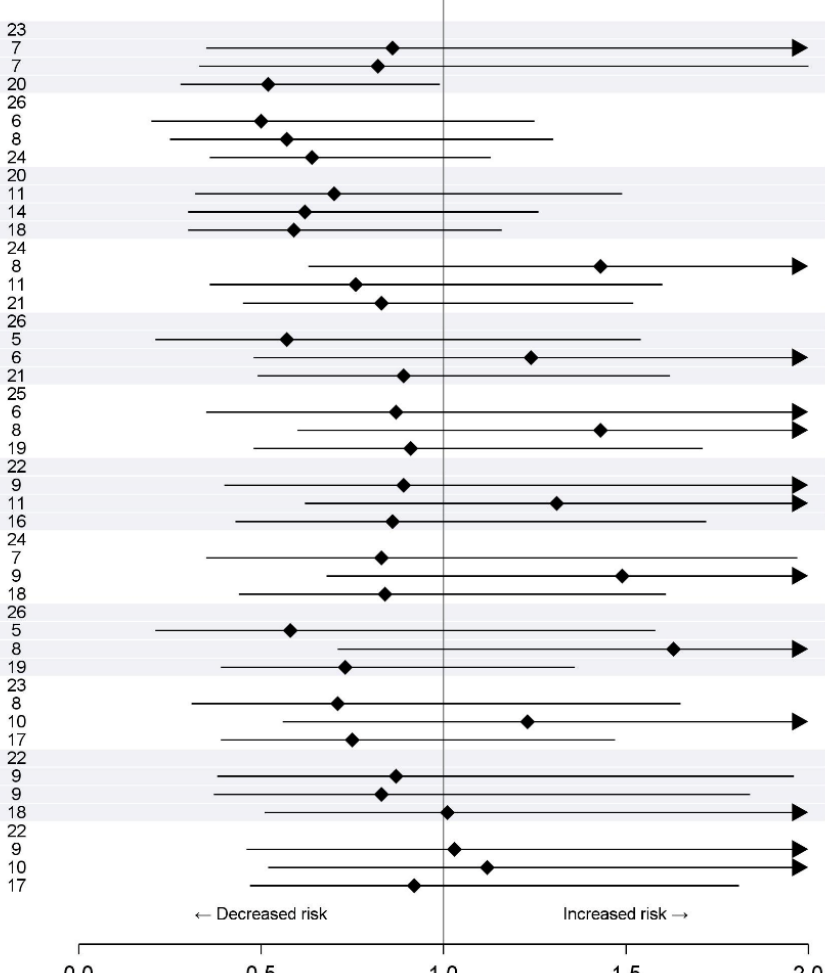

0.0

$$
(95 \% \mathrm{Cl}), \mathrm{p} \text {-value patients events }
$$

Adjusted HR [95\% Cl]

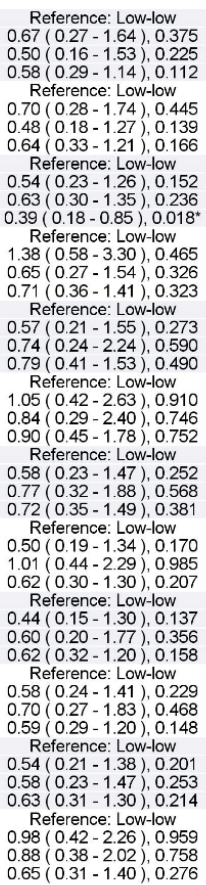

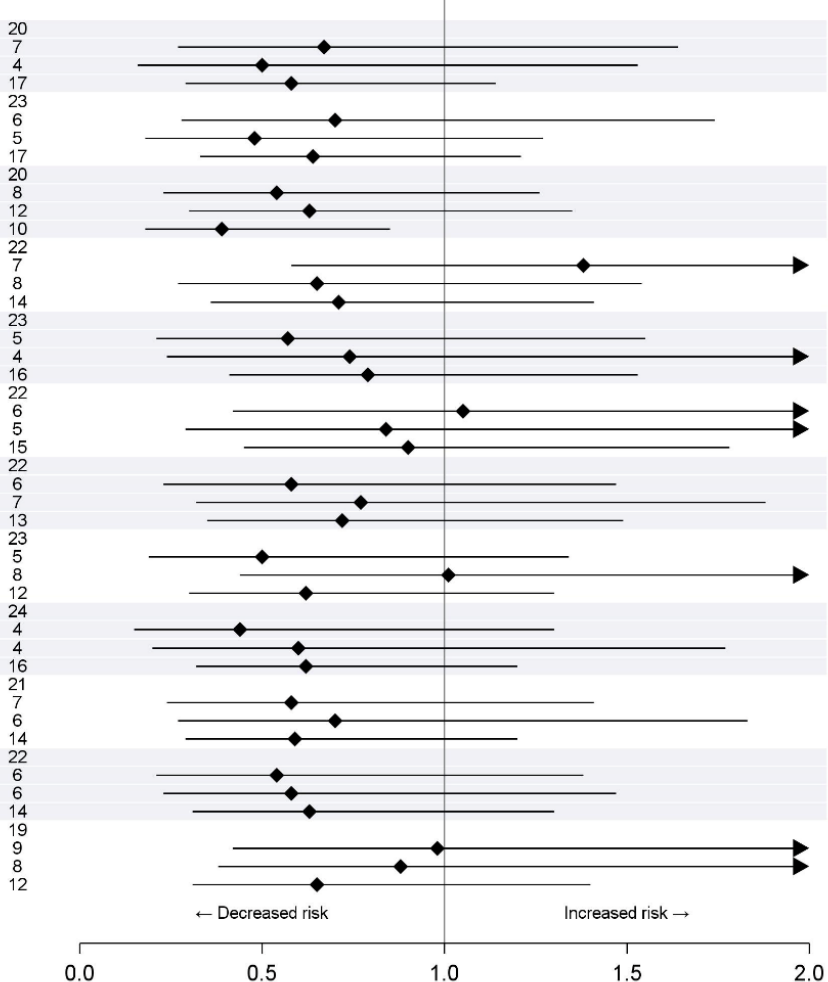

Figure 2. Effect of combination with CD8+ density on disease free survival (A) and overall survival (B) in the training cohort. Multivariable Cox proportional hazard models. * indicates significant $p$-value at 0.05 level. 
At multivariable analysis (Table S6), a longer DFS was statistically associated with higher $\mathrm{CD}^{+}$intratumoral density (aHR[100 cell $/ \mathrm{mm}^{2}$ increase $] 0.95,95 \% \mathrm{CI} 0.91-0.99, p=$ 0.027; aHR[high vs. low] $0.38,95 \%$ CI $0.19-0.78, p=0.008$ ) and higher CD3+ inner peritumoral density (aHR[100 cell $/ \mathrm{mm}^{2}$ increase] $\left.0.97,95 \% \mathrm{CI} 0.93-1.00, p=0.030\right)$. Moreover, higher intratumoral CD8 ${ }^{+}$density correlated with both DFS (aHR[100 cell $/ \mathrm{mm}^{2}$ increase] 0.94, 95\%CI 0.88-0.99, $p=0.030$; aHR[high vs. low] 0.23, 95\%CI 0.10-0.50, $p<0.001$ ) and OS (aHR[high vs. low] 0.30,95\%CI 0.13-0.70, $p=0.005$ ). Lastly, a beneficial impact on DFS (aHR[100 cell $/ \mathrm{mm}^{2}$ increase] 0.93, 95\%CI 0.88-0.98, $p=0.006$; aHR[high vs. low] 0.21, 95\%CI 0.08-0.52, $p<0.001$ ) and OS (aHR[100 cell $/ \mathrm{mm}^{2}$ increase] $0.93,95 \%$ CI 0.88-0.99, $p=0.015$; aHR[high vs. low] $0.23,95 \%$ CI $0.08-0.61, p=0.003$ ) was found in patients with high $\mathrm{CD}^{+}$density in the inner peritumoral environment.

Figure 3 summarizes the impact of the combination of the density and spatial distribution of $\mathrm{CD}^{+}$T-cells with other immune cells on DFS and OS. Consistent with the training cohort, in the validation cohort, patients with high density of both intratumoral CD8+ and $\mathrm{CD}^{+}$T-cells had a statistically better DFS (aHR[high-high vs. low-low] 0.24, 95\%CI $0.10-0.56, p<0.001)$ and those with high density of both intratumoral CD8 ${ }^{+}$and $\mathrm{CD}^{+} 8^{+}$had a statistically better OS (aHR[high-high vs. low-low] 0.28, 95\%CI 0.09-0.86, $p=0.025)$

A

Intratumoral CD3 CD8
High-low
Low-High
High-High
Intratumoral CD4 CD8
High-low
Low-High
High-High
Intratumoral CD68 CD8
High-low
Low-High
High-High
Peritumoral IN CD3 CD8
High-low
Low-High
High-High
Peritumoral IN CD4 CD8
High-low
Low-High

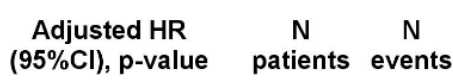

Adjusted HR [95\%Cl]

\begin{tabular}{|c|c|}
\hline Reference: Low-low & 39 \\
\hline $1.45(0.49-4.28), 0.496$ & 6 \\
\hline $0.19(0.02-1.49), 0.114$ & 2 \\
\hline $0.24(0.10-0.56),<0.001^{*}$ & 27 \\
\hline Reference: Low-low & 34 \\
\hline $3.02(1.27-7.15), 0.012^{*}$ & 11 \\
\hline $0.11(0.02-0.52), 0.005^{*}$ & 9 \\
\hline $0.45(0.18-1.14), 0.093$ & 20 \\
\hline Reference: Low-low & 24 \\
\hline $1.40(0.69-2.83), 0.348$ & 21 \\
\hline $0.53(0.15-1.85), 0.318$ & 7 \\
\hline $0.20(0.07-0.56), 0.002^{*}$ & 22 \\
\hline Reference: Low-low & 39 \\
\hline $1.48(0.56-3.89), 0.431$ & 8 \\
\hline $0.15(0.04-0.67), 0.013^{*}$ & 9 \\
\hline $0.27(0.09-0.80), 0.018^{*}$ & 15 \\
\hline Reference: Low-low & 40 \\
\hline $2.21(0.79-6.15), 0.130$ & 6 \\
\hline $0.16(0.04-0.61), 0.007^{*}$ & 10 \\
\hline $0.20(0.06-0.71), 0.012^{*}$ & 14 \\
\hline
\end{tabular}

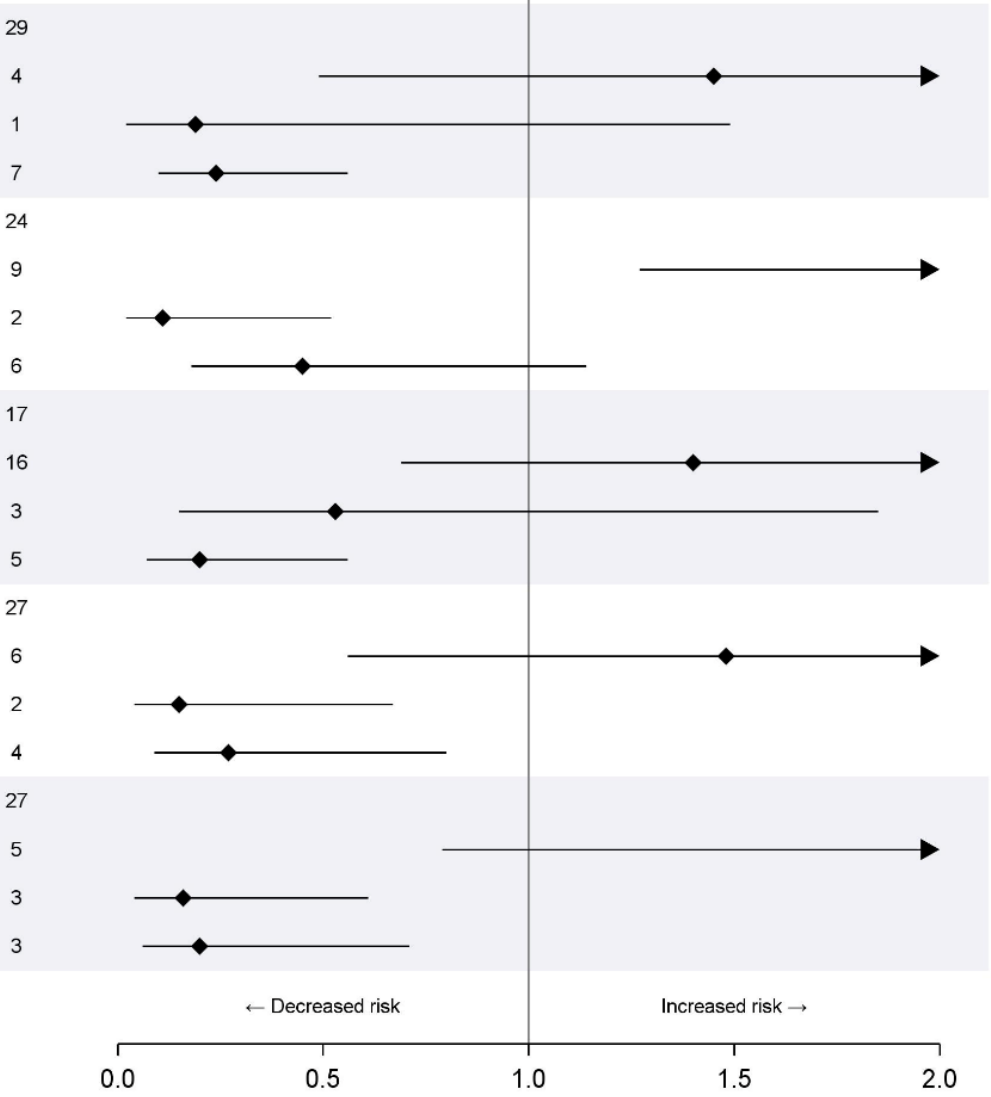

Figure 3. Cont. 
B

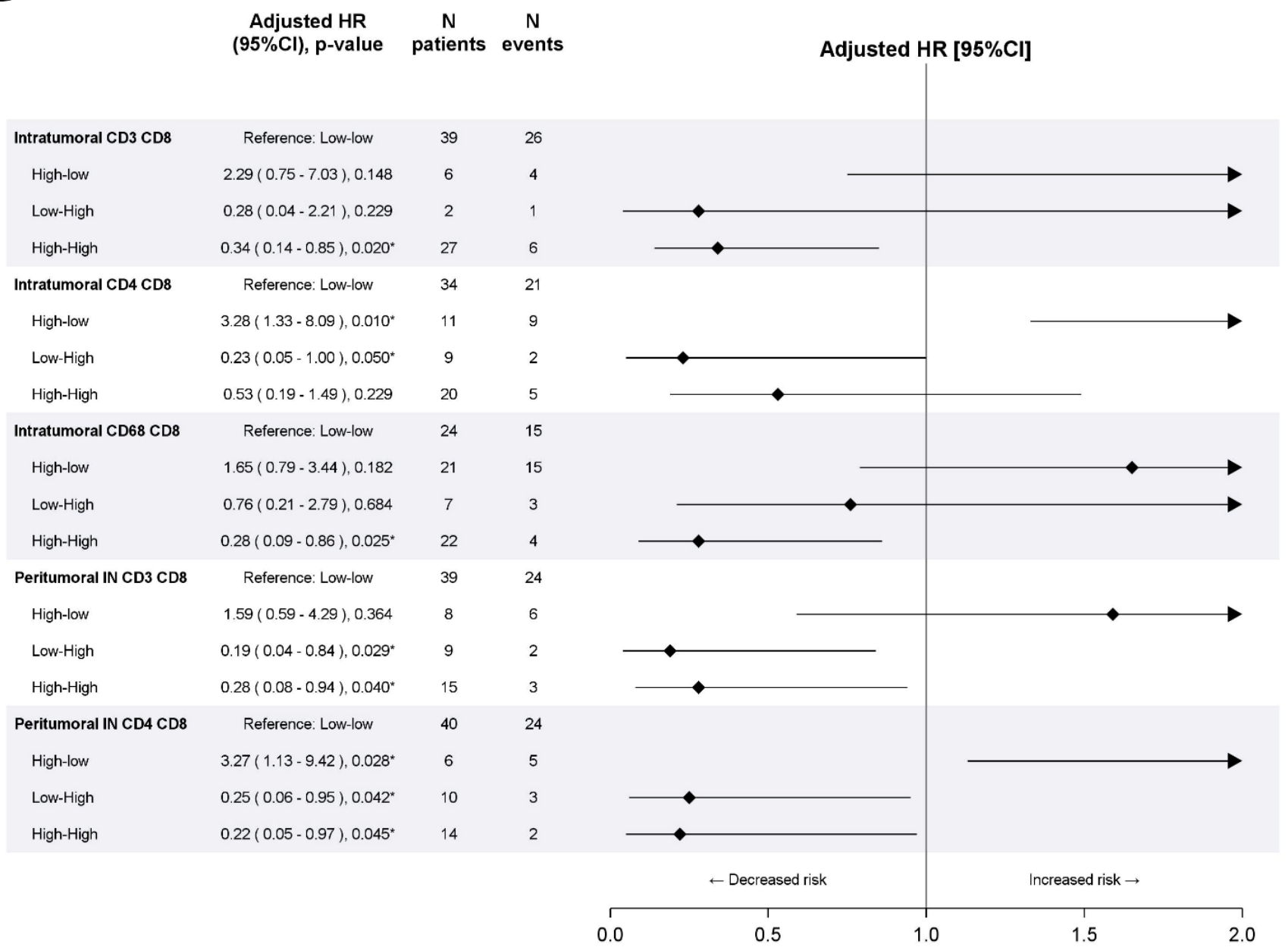

Figure 3. Effect of combination with $\mathrm{CD} 8^{+}$density on disease free survival (A) and overall survival (B) in the validation cohort. Multivariable Cox proportional hazard models.* indicates significant $p$-value at 0.05 level.

\section{Discussion}

The main result of our study is that the density and spatial distribution of $\mathrm{CD} 8^{+}$ T-cells and macrophages in the microenvironment predict DFS and OS in clinical stage II-III intermediate/thick PCM patients. The AJCC staging system acknowledges BT, ulceration, and SN status as the most reliable prognostic factors and, in daily practice, the AJCC classification has a considerable and direct impact on cancer patients' care. This is particularly true in the era of effective melanoma adjuvant therapies [21-23]. However, outcome prediction of the traditional staging system assumes that melanoma progression is a melanoma cell-autonomous process, and it does not consider the effects of the host immune response.

The interplay between melanoma and immune cells is a major determinant in melanoma progression and TILs are emerging as a powerful prognostic marker and therapeutic target in oncology [24,25]. Nevertheless, conventional evaluation of TILs is affected by interobserver variability and diverse scoring methods have been proposed $[15,26]$. Furthermore, TME includes a heterogeneous population, including not only T-lymphocytes, but also macrophages, and, to a lesser extent, B lymphocytes and natural killer cells [27,28]. Consequently, it is important to analyze spatial distribution of TILs subsets and macrophages separately through digital imaging and objective assessment due to their different physiopathological effects in the tumor microenvironment $[17,29,30]$. 
It has been reported in several models that cytotoxic memory $\mathrm{CD} 8^{+} \mathrm{T}$ cells $\left(\mathrm{CD}^{+}\right.$, $\mathrm{CD}^{+}, \mathrm{CD}^{2} 5 \mathrm{RO}^{+}$, Granzyme $\mathrm{B}^{+}$) are strongly associated with a favorable clinical outcome and it has been suggested to use a combination of any two of these four markers as prognostic factors $[28,31,32]$. Because of technical troubles, including background noise (CD45RO) and granular staining (Granzyme B), the two easiest membrane stains, CD3 and $\mathrm{CD} 8$, seem to be the most reliable biomarkers [28,32].

In our series, by using a digital quantification of $\mathrm{T}$ cytotoxic lymphocytes, we were able to predict the DFS and OS in stage II-III intermediate/thick PCM. Interestingly, the combination of two markers $\left(\mathrm{CD}^{+}\right.$and $\mathrm{CD} 8^{+} \mathrm{T}$ cells) in the intratumoral area significantly predicted the outcome. The fact that only intratumoral high density $\mathrm{CD}^{+}$and $\mathrm{CD} 8^{+} \mathrm{T}$ cells were more significant than total density may indicate that spatial distribution and quantification plays a role in melanoma immune surveillance.

In our study, the combination of high intratumoral $\mathrm{CD}^{+} \mathrm{T}$-cells and $\mathrm{CD} 8^{+} \mathrm{T}$-cells has been shown to be a favorable predictive biomarker at multivariable analysis. Melanoma patients that were characterized by an absence or low density of intratumoral infiltration showed higher recurrence rate and shorter OS. Specifically, the combined analysis of CD8 ${ }^{+}$ and CD3+ cells in the intratumoral location resulted in being a useful classification for the prediction of tumor recurrence in patients with intermediate/thick early stage PCM. At 5 -years of follow-up, the DFS and OS for patients with high density of intratumoral CD8 ${ }^{+}$ T-cell and $\mathrm{CD}^{+} \mathrm{T}$-cell were $43.4 \%$ and $63.6 \%$, respectively. Conversely, the DFS and OS rates of patients with low densities of these cells were $30.0 \%$ and $37.3 \%$ (log-rank test, DFS: $p=0.026)$.

Our results are partially in agreement with previous reports [13,33]. Piras et al. showed a significant difference in five-year survival among melanoma patient groups with high, moderate, and low $\mathrm{CD} 8^{+} \mathrm{T}$-cell density [34], irrespective of density and their spatial distribution.

Importantly, we found that inflamed melanomas, with high $\mathrm{CD}^{+}{ }^{+}$-cells and $\mathrm{CD} 8^{+}$ T-cells density or high $\mathrm{CD} 8^{+} \mathrm{T}$-cells and $\mathrm{CD}^{+} 8^{+}$macrophagic infiltration, have a better prognosis when compared to those with desert melanomas characterized by low $\mathrm{CD}^{+}$ and $\mathrm{CD} 8^{+} \mathrm{T}$-cell density or low $\mathrm{CD} 8^{+} \mathrm{T}$-cell and $\mathrm{CD} 68^{+}$macrophagic infiltration. This is in agreement with previous findings showing a better outcome for inflamed melanomas when compared to cold melanomas with a desert microenvironment [2].

From a clinical standpoint, our study adds information for intermediate-thick melanomas. Most of the findings on the prognostic role of TILs derive from studies that did not evaluate homogeneous cohorts of melanoma with $\mathrm{BT}>2 \mathrm{~mm}(7,8,14)$. Here, we show that the density and spatial distribution of T-cells play a role and predict the outcome of melanomas $\geq 2 \mathrm{~mm}$.

This study presents some points of strengths: (i) patients have been enrolled and treated homogeneously in Italian centers; (ii) automatic assessment upon digital image acquisition, which allows for unbiased and rapid quantification of the immune infiltrate in immunostained tissue sections and minimizes significant user errors due to categorical rankings; and, (iii) the validation of results in an independent cohort. However, we are aware of the study limitations, including: (i) the retrospective nature of the analysis of a prospective collected cohort of patients; (ii) the relatively small series in the training and the validation cohort; and, (iii) digital analysis cannot be considered to be a standard approach for the practicing pathologists and future prospective studies are needed to better understand the adding value of this technology as compared to the standard evaluation of TME in early stages melanoma patients.

Our findings suggest that a specific preexisting profile of $\mathrm{T}$ cells and macrophages distribution in melanomas may predict the risk of recurrence and death with potential implications for stratification of early stages melanoma patients. This may be particularly important in stage II AJCC melanoma patients, for whom new adjuvant treatments are not available and need to be better prognosticated. Because patients with absent/low intratumoral infiltration of $\mathrm{CD} 8^{+} \mathrm{T}$-cell have a statistically significant shorter DFS and 
OS, they may deserve further treatments to reduce the recurrence rate and ultimately progression of melanoma.

Supplementary Materials: The following are available online at https:/ / www.mdpi.com/2073-440 9/10/2/422/s1, Figure S1: Representative immunohistochemical images of CD3 (A), CD4 (B), CD8 (C) and CD68 (D) in melanoma tissue, Figure S2: Representative images of melanoma tissue with low CD8 (A) and low CD68 (B), Table S1: Biomarkers associations in the training cohort. Spearman correlation index., Table S2: Associations between biomarkers and clinical characteristics in the training cohort. Chi-square and Wilcoxon test, Table S3: Spatial distribution of biomarkers, Table S4: Biomarkers associations in the validation cohort. Spearman correlation index, Table S5: Associations between biomarkers and clinical characteristics in the validation cohort. Chi-square and Wilcoxon test, Table S6: Effect of biomarkers density on disease free survival and overall survival in the validation cohort. Univariable and multivariable Cox proportional hazard models.

Author Contributions: Conceptualization, D.M. and M.M.; methodology, F.D.L.; software, F.U.; validation, M.C., A.G. and C.M.; formal analysis, F.G., E.R.; investigation, A.C., F.D.L., F.G. and R.N.; resources, V.D.G.; data curation, F.G., E.R.; writing-original draft preparation, M.M. and D.M.; writing—review and editing, F.D.L., F.G., R.N.; visualization, S.S.; supervision, D.M. and M.M.; project administration, R.N.; funding acquisition, D.M. All authors have read and agreed to the published version of the manuscript.

Funding: This research was funded by the Fondazione AIRC "Programma di ricerca 5 per Mille 2018-ID\#21073" to EPICA investigators.

Institutional Review Board Statement: The study was conducted according to the guidelines of the Declaration of Helsinki, and approved by the Ethics Committee of the Florence University Hospital (Area Vasta Toscana Centro) (13676_bio, protocol Id.21073 01/29/2019).

Informed Consent Statement: Informed consent was obtained from all subjects involved in the study.

Data Availability Statement: The data presented in this study are available on request from the corresponding author.

Conflicts of Interest: The authors declare no conflict of interest.

\section{References}

1. Palucka, A.K.; Coussens, L.M. The basis of oncoimmunology. Cell 2016, 164, 1233-1247. [CrossRef]

2. Teng, M.W.L.; Ngiow, S.F.; Ribas, A.; Smyth, M.J. Classifying cancers based on T-cell infil-tration and PD-L1. Cancer Res. 2015, 75, 2139-2145. [CrossRef]

3. Poźniak, J.; Nsengimana, J.; Laye, J.P.; O’Shea, S.J.; Diaz, J.M.S.; Droop, A.P.; Filia, A.; Harland, M.; Davies, J.R.; Mell, T.; et al. Genetic and Environmental Determinants of Immune Response to Cutaneous Melanoma. Cancer Res. 2019, 79, $2684-2696$. [CrossRef] [PubMed]

4. Chen, D.S.; Mellman, D.S.C.I. Elements of cancer immunity and the cancer-immune set point. Nat. Cell Biol. 2017, 541, 321-330. [CrossRef] [PubMed]

5. Curtin, J.A.; Fridlyand, J.; Kageshita, T.; Patel, H.N.; Busam, K.J.; Kutzner, H.; Cho, K.-H.; Aiba, S.; Bröcker, E.-B.; LeBoit, P.E.; et al. Distinct Sets of Genetic Alterations in Melanoma. N. Engl. J. Med. 2005, 353, 2135-2147. [CrossRef] [PubMed]

6. Mandalà, M.; Massi, D. Tissue prognostic biomarkers in primary cutaneous melanoma. Virchows Arch. 2014, 464, 265-281. [CrossRef] [PubMed]

7. Taylor, R.C.; Patel, A.; Panageas, K.S.; Busam, K.J.; Brady, M.S. Tumor-Infiltrating Lymphocytes Predict Sentinel Lymph Node Positivity in Patients With Cutaneous Melanoma. J. Clin. Oncol. 2007, 25, 869-875. [CrossRef] [PubMed]

8. Azimi, F.; Scolyer, R.A.; Rumcheva, P.; Moncrieff, M.; Murali, R.; McCarthy, S.W.; Saw, R.P.; Thompson, J.F. Tumor-Infiltrating Lymphocyte Grade Is an Independent Predictor of Sentinel Lymph Node Status and Survival in Patients With Cutaneous Melanoma. J. Clin. Oncol. 2012, 30, 2678-2683. [CrossRef] [PubMed]

9. Thomas, N.E.; Busam, K.J.; From, L.; Kricker, A.; Armstrong, B.K.; Anton-Culver, H.; Gruber, S.B.; Gallagher, R.P.; Zanetti, R.; Rosso, S.; et al. Tumor-Infiltrating Lymphocyte Grade in Primary Melanomas Is Independently Associated With MelanomaSpecific Survival in the Population-Based Genes, Environment and Melanoma Study. J. Clin. Oncol. 2013, 31, 4252-4259. [CrossRef] [PubMed]

10. De Moll, E.H.; Fu, Y.; Qian, Y.; Perkins, S.H.; Wieder, S.Y.; Gnjatic, S.; Remark, R.; Bernardo, S.G.; Moskalenko, M.; Yao, J.; et al. Immune biomarkers are more accurate in prediction of survival in ulcerated than in non-ulcerated primary melanomas. Cancer Immunol. Immunother. 2015, 64, 1193-1203. [CrossRef] 
11. Donizy, P.; Kaczorowski, M.; Halon, A.; Leskiewicz, M.; Kozyra, C.; Matkowski, R. Paucity of tumor-infiltrating lymphocytes is an unfavorable prognosticator and predicts lymph node metastases in cutaneous melanoma patients. Anticancer Res. 2015, 35, 351-358.

12. Letca, A.F.; Ungureanu, L.; Șenilă, S.C.; Grigore, L.E.; Pop, S.; Fechete, O.; Vesa, Ş.C.; Cosgarea, R. Regression and Sentinel Lymph Node Status in Melanoma Progression. Med. Sci. Monit. 2018, 24, 1359-1365. [CrossRef] [PubMed]

13. Fu, Q.; Chen, N.; Ge, C.; Li, R.; Li, Z.; Zeng, B.; Li, C.; Wang, Y.; Xue, Y.; Song, X.; et al. Prognostic value of tumor-infiltrating lymphocytes in melanoma: A systematic review and meta-analysis. OncoImmunology 2019, 8, e1593806. [CrossRef]

14. Mandalà, M.; Imberti, G.; Piazzalunga, D.; Belfiglio, M.; Labianca, R.; Barberis, M.; Marchesi, L.; Poletti, P.; Bonomi, L.; Novellino, L.; et al. Clinical and histopathological risk factors to predict sentinel lymph node positivity, disease-free and overall survival in clinical stages I-II AJCC skin melanoma: Outcome analysis from a single-institution prospectively collected database. Eur. J. Cancer 2009, 45, 2537-2545. [CrossRef] [PubMed]

15. Busam, K.J.; Antonescu, C.R.; Marghoob, A.A.; Nehal, K.S.; Sachs, D.L.; Shia, J.; Berwick, M. Histologic Classification of Tumor-Infiltrating Lymphocytes in Primary Cutaneous Malignant Melanoma. Am. J. Clin. Pathol. 2001, 115, 856-860. [CrossRef] [PubMed]

16. Mantovani, A.; Marchesi, F.; Malesci, A.; Laghi, L.; Allavena, P. Tumour-associated macrophages as treatment targets in oncology. Nat. Rev. Clin. Oncol. 2017, 14, 399-416. [CrossRef] [PubMed]

17. Gartrell, R.D.; Marks, D.K.; Hart, T.D.; Li, G.; Davari, D.R.; Wu, A.; Blake, Z.; Lu, Y.; Askin, K.N.; Monod, A.; et al. Quantitative Analysis of Immune Infiltrates in Primary Melanoma. Cancer Immunol. Res. 2018, 6, 481-493. [CrossRef] [PubMed]

18. Gershenwald, J.E.; Scolyer, R.A.; Hess, K.R.; Sondak, V.K.; Long, G.V.; Ross, M.I.; Lazar, A.J.; Faries, M.B.; Kirkwood, J.M.; McArthur, G.A.; et al. Melanoma staging: Evidence-based changes in the American Joint Committee on Cancer eighth edition cancer staging manual. CA Cancer J. Clin. 2017, 67, 472-492. [CrossRef]

19. Clark, W.H.; Elder, D.E.; Guerry, D.; Braitman, L.E.; Trock, B.J.; Schultz, D.; Synnestvedt, M.; Halpern, A.C. Model Predicting Survival in Stage I Melanoma Based on Tumor Progression. J. Natl. Cancer Inst. 1989, 81, 1893-1904. [CrossRef] [PubMed]

20. Parra, E.R.; Behrens, C.; Rodriguez-Canales, J.; Lin, H.; Mino, B.; Blando, J.; Zhang, J.; Gibbons, D.L.; Heymach, J.V.; Sepesi, B.; et al. Image Analysis-based Assessment of PD-L1 and Tumor-Associated Immune Cells Density Supports Distinct Intratumoral Microenvironment Groups in Non-small Cell Lung Carcinoma Patients. Clin. Cancer Res. 2016, 22, 6278-6289. [CrossRef] [PubMed]

21. Eggermont, A.M.; Chiarion-Sileni, V.; Grob, J.-J.; Dummer, R.; Wolchok, J.D.; Schmidt, H.; Hamid, O.; Robert, C.; Ascierto, P.A.; Richards, J.M.; et al. Prolonged Survival in Stage III Melanoma with Ipilimumab Adjuvant Therapy. N. Engl. J. Med. 2016, 375, 1845-1855. [CrossRef]

22. Hauschild, A.; Dummer, R.; Schadendorf, D.; Santinami, M.; Atkinson, V.; Mandalà, M.; Chiarion-Sileni, V.; Larkin, J.; Nyakas, M.; Dutriaux, C.; et al. Longer Follow-Up Confirms Relapse-Free Survival Benefit with Adjuvant Dabrafenib Plus Trametinib in Patients With Resected BRAF V600-Mutant Stage III Melanoma. J. Clin. Oncol. 2018, 36, 3441-3449. [CrossRef] [PubMed]

23. Weber, J.; Mandalà, M.; Del Vecchio, M.; Gogas, H.; Arance, A.M.; Cowey, C.L.; Dalle, S.; Schenker, M.; Chiarion-Sileni, V.; Marquez-Rodas, I.; et al. Adjuvant Nivolumab versus Ipilimumab in Resected Stage III or IV Melanoma. N. Engl. J. Med. 2017, 377, 1824-1835. [CrossRef] [PubMed]

24. Tuccitto, A.; Shahaj, E.; Vergani, E.; Ferro, S.; Huber, V.; Rodolfo, M.; Castelli, C.; Rivoltini, L.; Vallacchi, V. Immunosuppressive circuits in tumor microenvironment and their influence on cancer treatment efficacy. Virchows Arch. 2019, 474, 407-420. [CrossRef] [PubMed]

25. Mandalà, M.; Rutkowski, P. Rational combination of cancer immunotherapy in melanoma. Virchows Arch. 2018, 474, 433-447. [CrossRef] [PubMed]

26. Němejcová, K.; Tichá, I.; Bártů, M.; Kodet, O.; Důra, M.; Jakša, R.; Michálková, R.; Dundr, P. Comparison of five different scoring methods in the evaluation of inflammatory infiltration (tumor-infiltrating lymphocytes) in superficial spreading and nodular melanoma. Pigment. Cell Melanoma Res. 2019, 32, 412-423. [CrossRef]

27. Galon, J.; Costes, A.; Sanchez-Cabo, F.; Kirilovsky, A.; Mlecnik, B.; Lagorce-Pagès, C.; Tosolini, M.; Camus, M.; Berger, A.; Wind, P.; et al. Type, Density, and Location of Immune Cells Within Human Colorectal Tumors Predict Clinical Outcome. Science 2006, 313, 1960-1964. [CrossRef] [PubMed]

28. Galon, J.; Pagès, F.; Marincola, F.M.; Angell, H.K.; Thurin, M.; Lugli, A.; Zlobec, I.; Berger, A.; Bifulco, C.; Botti, G.; et al. Cancer classification using the Immunoscore: A worldwide task force. J. Transl. Med. 2012, 10, 205. [CrossRef]

29. Wang, J.-J.; Lei, K.-F.; Han, F. Tumor microenvironment: Recent advances in various cancer treatments. Eur. Rev. Med Pharmacol. Sci. 2018, 22, 3855-3864.

30. Pagès, F.; Mlecnik, B.; Marliot, F.; Bindea, G.; Ou, F.-S.; Bifulco, C.; Lugli, A.; Zlobec, I.; Rau, T.T.; Berger, M.D.; et al. International validation of the consensus Immunoscore for the classification of colon cancer: A prognostic and accuracy study. Lancet 2018, 391, 2128-2139. [CrossRef]

31. Galon, J.; Mlecnik, B.; Bindea, G.; Angell, H.K.; Berger, A.; Lagorce, C.; Lugli, A.; Zlobec, I.; Hartmann, A.; Bifulco, C.; et al. Towards the introduction of the 'Immunoscore' in the classification of malignant tumours. J. Pathol. 2014, 232, 199-209. [CrossRef] [PubMed] 
32. Guo, W.; Lu, X.; Liu, Q.; Zhang, T.; Li, P.; Qiao, W.; Deng, M. Prognostic value of neutrophil-to-lymphocyte ratio and plateletto-lymphocyte ratio for breast cancer patients: An updated meta-analysis of 17079 individuals. Cancer Med. 2019, 8, 4135-4148. [CrossRef] [PubMed]

33. Clemente, C.G.; Mihm, M.C.; Bufalino, R.; Zurrida, S.; Collini, P.; Cascinelli, N. Prognostic value of tumor infiltrating lymphocytes in the vertical growth phase of primary cutaneous melanoma. Cancer 1996, 77, 1303-1310. [CrossRef]

34. Piras, F.; Colombari, R.; Minerba, L.; Murtas, D.; Floris, C.; Maxia, C.; Corbu, A.; Perra, M.T.; Sirigu, P. The predictive value of $\mathrm{CD} 8, \mathrm{CD} 4, \mathrm{CD} 68$, and human leukocyte antigen-D-related cells in the prognosis of cutaneous malignant melanoma with vertical growth phase. Cancer 2005, 104, 1246-1254. [CrossRef] [PubMed] 